\title{
Solid-liquid axial dispersion performance of a mesoscale continuous oscillatory flow crystalliser with smooth periodic constrictions using a non-invasive dual backlit imaging technique
}

\author{
Iyke. I. Onyemelukwe ${ }^{\mathrm{a}}$, Zoltan K. Nagy ${ }^{\mathrm{a}, \mathrm{b}}$, Chris. D. Riellya, ${ }^{\mathrm{a}}$ \\ ${ }^{a}$ EPSRC Centre for Innovative Manufacturing in Continuous Manufacturing and Crystallisation, \\ Department of Chemical Engineering, Loughborough University, Loughborough, Leicestershire LE11 \\ $3 T U, U K$ \\ ${ }^{\mathrm{b}}$ School of Chemical Engineering, Purdue University, West Lafayette, IN 47907, USA \\ ${ }^{\dagger}$ Email: c.d.rielly@lboro.ac.uk
}

\begin{abstract}
A dual backlit imaging technique has been developed for liquid and solid phase residence time distribution (RTD) measurements in a mesoscale (millilitre) continuous oscillatory flow crystalliser with smooth periodic constrictions (herein known as the SPC mesoscale crystalliser). The pixel-based technique enables reliable determination and direct comparison of experimentally determined hydrodynamic parameters for the liquid and solid phase without concern for errors that may be introduced by utilising different measurement techniques for each phase. Additionally, the non-invasive technique offers benefits over traditional intrusive methods as demonstrated herein. Results of solid-liquid RTD experiments reveal that for a set of oscillatory flow conditions, particles do not experience the same degree of axial dispersion and mean residence time as the continuous liquid phase. The SPC mesoscale crystalliser, however, provides solid-liquid plug flow at low net flow rates. Findings in this work emphasise the importance of characterising solid phase axial dispersion for active pharmaceutical ingredient (API) systems during continuous crystallisation development to identify minimum dispersion operating conditions essential for solid-liquid plug flow crystallisation.
\end{abstract}


Keywords: mesoscale, oscillatory flow, smooth periodic constrictions, dual backlit imaging, residence time distribution, solid phase dispersion

\section{Introduction}

Mesoscale oscillatory flow reactors (OFRs) with smooth periodic constriction (SPC) geometries are oscillatory flow mixing (OFM) devices $[1,2]$ that in recent times have been increasingly applied to solids handling processes such as crystallisation because of their efficient fluid mixing and particle suspension characteristics [3,4]. Mesoscale OFRs (typically $<10 \mathrm{~mm}$ i.d.) are primarily developed for laboratory scale processes [5] and are designed to scale up to pilot scale directly [6]. As such, they are well suited for developing intensified laboratory scale crystallisation processes with minimal use of raw materials, a purpose for which they are also known as mesoscale oscillatory flow crystallisers (OFCs) or mesoscale crystallisers. Castro et al. [7] performed the batch precipitation of hydroxyapatite nanoparticles in a $4 \mathrm{~mm}$ i.d. mesoscale OFR with SPC geometry. The precipitation reaction completed four times faster, producing nanoparticles with improved characteristics. Castro et al. [8] reported the first protein crystallisation of lysozyme in a $3 \mathrm{~mm}$ i.d. SPC mesoscale OFR, where oscillatory flow mixing promoted nucleation at quiescent conditions. Cruz et al. [9] studied the batch and continuous crystallisation of paracetamol in a $4 \mathrm{~mm}$ i.d. SPC mesoscale OFR, demonstrating the effect of oscillatory mixing conditions on paracetamol crystal size and size distribution.

The fluid mechanics in an OFM device is governed by three dimensionless groups relating to oscillatory flow namely the oscillatory Reynolds number, $R e_{o}$, the net flow Reynolds number, $R e_{n}$, and the Strouhal number, $S t$, which are defined as: 


$$
\begin{aligned}
& R e_{o}=\frac{2 \pi f x_{0} \rho D}{\mu} \\
& R e_{n}=\frac{\rho u D}{\mu} \\
& S t=\frac{D}{4 \pi x_{0}}
\end{aligned}
$$

where $\rho$ is the fluid density, $D$ is the internal diameter of the tube, $x_{0}$ is the centre-to-peak oscillation amplitude, $f$ is the oscillation frequency, $u$ is the superficial velocity, and $\mu$ is the fluid viscosity. $R e_{o}$ describes the intensity of mixing applied in the tube, while $S t$ is the ratio of tube diameter to stroke length, in other words it characterises the effective eddy propagation [10]. When $S t=\infty$, the absence of eddy generation to effectively mix the interbaffle/constriction cavity results in flows that are dominated by viscosity and density effects, with high axial dispersion along the length of the tube [11]. An additional dimensionless group is the velocity ratio, $\varphi$, which describes the interdependence of the oscillatory and net flow components:

$$
\varphi=\frac{R e_{o}}{R e_{n}}
$$

Usually, oscillatory flow must be dominant for full flow reversal and efficient mixing to occur; for this to happen, $\varphi$ must be at least greater than 1 [12].

It has previously been demonstrated that an appropriate combination of oscillatory frequency and centre-to-peak amplitude can minimise liquid axial dispersion (backmixing) in mesoscale OFRs between $4-10 \mathrm{~mm}$ i.d., making it possible to approach a plug flow RTD at 
very low net flow rates. Reis et al [13] identified the minimum liquid backmixing conditions in a novel $4.4 \mathrm{~mm}$ i.d. SPC mesoscale OFR as $x_{0}=0.5-1 \mathrm{~mm}$ and $f=7.5-10 \mathrm{~Hz}$. Reis et al. [14] also found minimum axial dispersion in a $4.5 \mathrm{~mm}$ i.d. SPC mesoscale OFR for values of $x_{0} \leq 1 \mathrm{~mm}$ and $f=10 \mathrm{~Hz}$. As shown in Table 1 , the oscillatory conditions identified for near plug flow behaviour can vary for different meso-tube diameters and baffle designs. Minimum dispersion conditions can also vary across geometries of mesoscale OFRs $[15,16]$, and vary with operating net flow rates $[17,18]$. In addition, the experimentally determined values of hydrodynamic parameters (i.e. axial dispersion coefficient, $D_{a x}$, and number of tanksin-series, $n$ ) which are used in continuous reactor/crystalliser models in digital design are very dependent on measurement methods (as demonstrated herein) and numerical fitting techniques employed [14,19]. Therefore, for any continuous platform development, it is an essential first step to critically evaluate the hydrodynamic performance using suitable methods, rather than relying solely on literature reporting. It is worth noting that intrusive techniques such as fibre optics and conductivity probes have so far been the most common way of measuring axial dispersion in mesoscale OFRs.

While numerous studies clearly show the suitability of mesoscale OFRs for achieving narrow RTDs, many of these studies have only investigated axial dispersion of the liquid phase, neglecting solid phase behaviour. Ejim et al. [15], employing a washout (step input) of monodispersed polyvinyl chloride (PVC) particles and a CCD camera, measured the axial dispersion of solid-liquid flow in different geometrical designs of $10 \mathrm{~mm}$ i.d. mesoscale OFRs and assumed that the axial dispersion in mesoscale OFRs is comparable to axial dispersion in liquid-only flow. 
Table 1 Minimum axial dispersion conditions for different mesoscale OFR designs

\begin{tabular}{|c|c|c|c|c|c|c|}
\hline $\begin{array}{l}\text { Mesoscale } \\
\text { OFR } \\
\text { i.d. }(\mathrm{mm})\end{array}$ & $\begin{array}{l}\text { Baffle } \\
\text { design }\end{array}$ & $\begin{array}{l}\text { Minimum } \\
\text { dispersion range }\end{array}$ & $\begin{array}{l}\text { Oscillatory } \\
\text { range studied }\end{array}$ & $\begin{array}{l}\text { Flow rates } \\
\left(\mathrm{ml} \mathrm{min} \mathrm{min}^{-1}\right)\end{array}$ & $\begin{array}{l}\text { Tracer/ } \\
\text { technique }\end{array}$ & Reference \\
\hline 4.4 & SPC & $\begin{array}{l}x_{0}=0.5-1 \mathrm{~mm} \\
f=7.5-10 \mathrm{~Hz}\end{array}$ & $\begin{array}{l}x_{0}=0-3 \mathrm{~mm} \\
f=0-20 \mathrm{~Hz}\end{array}$ & 1.94 & $\begin{array}{l}\text { Indigo carmine/ } \\
\text { fibre optic } \\
\text { probes }\end{array}$ & Reis et al. [13] \\
\hline 4.5 & SPC & $\begin{array}{l}x_{0}=0.5-1 \mathrm{~mm} \\
f=10 \mathrm{~Hz}\end{array}$ & $\begin{array}{l}x_{0}=0-3 \mathrm{~mm} \\
f=0-20 \mathrm{~Hz}\end{array}$ & 1.94 & $\begin{array}{l}\text { Indigo carmine/ } \\
\text { fibre optic } \\
\text { probes }\end{array}$ & Reis et al. [14] \\
\hline 5 & SPC & $\begin{array}{l}x_{0}=0.5-1 \mathrm{~mm} \\
f=10-12 \mathrm{~Hz}\end{array}$ & $\begin{array}{l}x_{0}=0-3 \mathrm{~mm} \\
f=2-12 \mathrm{~Hz}\end{array}$ & $2.3-13.7$ & $\begin{array}{l}\text { Indigo carmine/ } \\
\text { optical probes }\end{array}$ & $\begin{array}{l}\text { Zheng and } \\
\text { Mackley [18] }\end{array}$ \\
\hline 4 & $\begin{array}{l}\text { Hexagonal } \\
\text { discs }\end{array}$ & $\begin{array}{l}x_{0}=0.5-1 \mathrm{~mm} \\
f=4 \mathrm{~Hz}\end{array}$ & $\begin{array}{l}x_{0}=0-4 \mathrm{~mm} \\
f=1-6 \mathrm{~Hz}\end{array}$ & $1-8$ & $\begin{array}{l}\mathrm{KCl} / \\
\text { conductivity }\end{array}$ & $\begin{array}{l}\text { Phan et al. [17]; } \\
\text { Phan and }\end{array}$ \\
\hline 5 & $\begin{array}{l}\text { Helical } \\
\text { coil inserts }\end{array}$ & $\begin{array}{l}x_{0}=2-4 \mathrm{~mm} \\
f=3 \mathrm{~Hz}\end{array}$ & $\begin{array}{l}x_{0}=0-4 \mathrm{~mm} \\
f=1-6 \mathrm{~Hz}\end{array}$ & $1-8$ & probes & Harvey [20] \\
\hline 5 & SPC & $\begin{array}{l}x_{0}=0.5-1 \mathrm{~mm} \\
f=3 \mathrm{~Hz}\end{array}$ & $\begin{array}{l}x_{0}=0-4 \mathrm{~mm} \\
f=1-6 \mathrm{~Hz}\end{array}$ & $1-8$ & & \\
\hline 6 & $\begin{array}{l}\text { Integral } \\
\text { baffles }\end{array}$ & $\begin{array}{l}x_{0}=1 \mathrm{~mm} \\
f=1.5 \mathrm{~Hz}\end{array}$ & $\begin{array}{l}x_{0}=1-10 \mathrm{~mm} \\
f=0.2-3 \mathrm{~Hz}\end{array}$ & $10-30$ & $\begin{array}{l}\text { Methylene blue/ } \\
\text { microscope } \\
\text { camera }\end{array}$ & Oliva et al. [21] \\
\hline 8 & SPC planar & $\begin{array}{l}V_{d} / V_{\text {cell }}=1 \\
f=3-4.5 \mathrm{~Hz}\end{array}$ & $\begin{array}{l}V_{d} / V_{\text {cell }}= \\
0.6-1 \\
f=3-6 \mathrm{~Hz}\end{array}$ & $16-109$ & $\begin{array}{l}\text { Indigo carmine, } \\
\text { PVC particles/ } \\
\text { UV-Vis } \\
\text { spectrometer }\end{array}$ & Cruz et al. [16] \\
\hline 10 & SPC & $\begin{array}{l}x_{0}=0.5-3 \mathrm{~mm} \\
f=7 \mathrm{~Hz}\end{array}$ & $\begin{array}{l}x_{0}=0-3 \mathrm{~mm} \\
f=0-20 \mathrm{~Hz}\end{array}$ & 17.8 & $\begin{array}{l}\text { PVC particles/ } \\
\text { CCD camera }\end{array}$ & Ejim et al. [15] \\
\hline 10 & SEPC & $\begin{array}{l}x_{0}=0.5-3 \mathrm{~mm} \\
f=7 \mathrm{~Hz}\end{array}$ & $\begin{array}{l}x_{0}=0-3 \mathrm{~mm} \\
f=0-20 \mathrm{~Hz}\end{array}$ & 17.8 & & \\
\hline
\end{tabular}

These authors however drew no direct comparison between dispersion behaviour of the solid and liquid phase in the $1 \mathrm{~m}$ long $10 \mathrm{~mm}$ i.d. tubes investigated. In contrast, Kacker et al. [22] using pulse input experiments of melamine crystals and an FBRM probe, showed that in a 15 $\mathrm{mm}$ i.d. conventional scale continuous oscillatory baffled crystalliser (COBC) the optimal oscillatory conditions for minimising dispersion are different for the heterogeneous (solidliquid flow) and homogeneous (liquid flow) system. Comparisons were drawn using in situ absorbance spectrophotometry and methylene blue tracer for the homogeneous experiments. Recently, Cruz et al. [16] investigated liquid and solid phase axial dispersion in three $8 \mathrm{~mm}$ i.d. OFCs possessing a planar geometry. Utilising a UV/Vis spectrometer and a flow cell to determine and compare the liquid and solid hydrodynamic parameters, the authors concluded that similar axial dispersion performances of the liquid and solid phases were obtained in all three planar-OFCs. However, in general, particles do not follow exactly the fluid flow, and may not be transported at the same velocity or with the same degree of axial dispersion as the 
liquid continuous phase for a set of oscillatory conditions. This is mainly for two reasons: (i) particles have inertia and (ii) the drag force causes particles to accelerate towards the local liquid velocity [23]. Many crystallisation simulations are often performed with the assumption that crystals experience the exact flow conditions as the bulk liquid and share the same RTD, whereas in practice this may not be the case.

To address this issue, a dual backlit imaging technique has been developed to measure the separate RTDs of the liquid and solid phase in a $5 \mathrm{~mm}$ i.d. SPC mesoscale crystalliser. This image-based method comprises two backlit detectors positioned separately along the SPC mesoscale crystalliser, to measure the inlet and outlet concentration profiles from the test section. The use of dual detectors enables the implementation of an imperfect pulse method to eliminate difficulties associated with an inaccurate pulse injection and measurement, since a perfect input function is difficult to achieve practically. More importantly, the technique enables direct comparison of the hydrodynamic parameters for the liquid and solid phase without concern for errors that may be introduced by employing different measurement techniques for each phase. This will help understand the mixing behaviour of crystals in comparison to the continuous liquid phase under different fluid oscillatory conditions in tubular crystallisers. The technique also overcomes the limitations of traditional intrusive measurements, whereby probes can only be fitted at specific locations, or at the end of the OFM device using specially designed ports or accessories. By means of a traversing platform, both detectors can easily be mounted at any distance apart to vary the length of the test section in the crystalliser without distorting the flow. In recent times, non-invasive image-based methods have been successfully employed for RTD investigations. Ejim et al. [15] used a single CCD camera to determine RTDs in mesoscale OFRs. Oliva et al. [21] utilised a single microscope camera and principal component-based image analysis to determine the dispersion coefficients in a mesoscale OFR (DN-6) and conventional scale COBR (DN-15). While image-based 
techniques are growing in use for RTD measurements, no direct comparisons with traditional techniques have been reported to date.

Zheng and Mackley [18] previously reported an optimum oscillatory range of $x_{0}=0.5$ $-1 \mathrm{~mm}$ and $f=10 \mathrm{~Hz}$ for liquid phase plug flow in the OFM device herein presented. The authors did not, however, investigate the corresponding solid phase axial dispersion at these conditions. This paper presents the characterisation of the liquid and solid phase axial dispersion performance of the SPC mesoscale crystalliser to understand how oscillatory flow conditions can be manipulated to control solid-liquid RTD and approach the behaviour of a perfect plug flow crystalliser (PFC), which is essential for providing a uniform hydrodynamic environment for crystals in continuous crystallisation. Firstly, an interpretation of fitted RTD curves is performed to provide information on the liquid backmixing behaviour of the SPC mesoscale crystalliser, and an optimal range of oscillatory conditions is identified based on the liquid axial dispersion number estimated. A similar procedure is then carried out to determine the corresponding solid axial dispersion in the optimal range of operating conditions identified for the liquid phase.

\section{Experimental methods}

\subsection{SPC geometry}

Figure 1 shows the meso-tube geometry of the SPC mesoscale crystalliser herein investigated. The SPC meso-tube has an internal diameter, $D$, of $5 \mathrm{~mm}$ and an inner constriction diameter, $d_{0}$, of $2.0 \mathrm{~mm}$ which gives an open cross-sectional area, $\alpha$, of $16 \%$. The mean spacing between smooth constrictions, $l$, is $13 \mathrm{~mm}$, giving a constriction length-to-diameter ratio, $l / D$, of 2.6. 


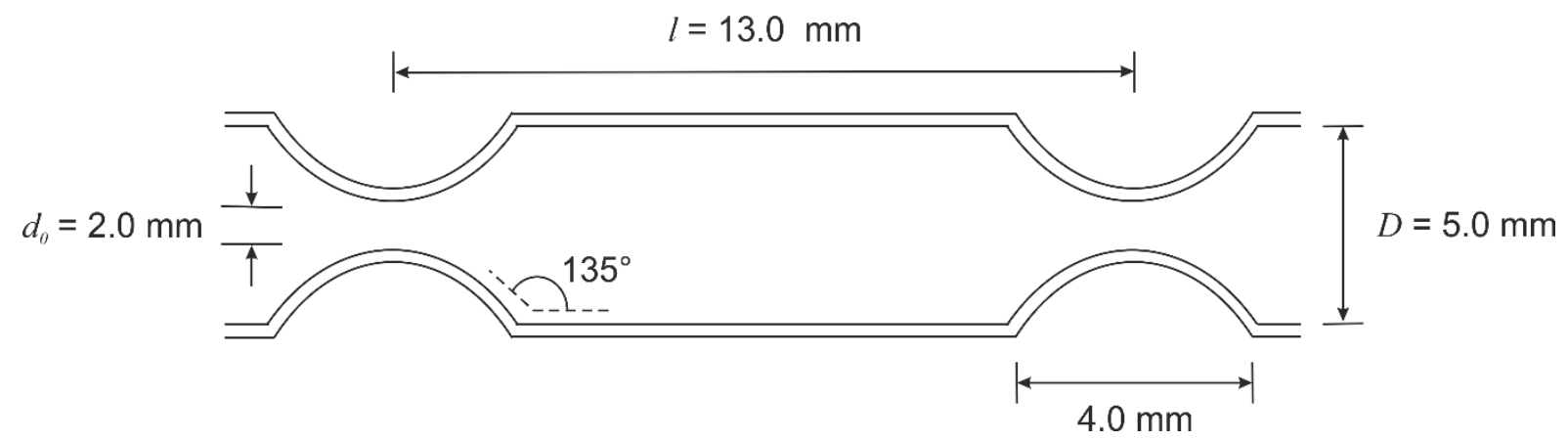

Figure 1 Schematic of SPC meso-tube with labelled dimensions.

\subsection{SPC mesoscale crystalliser}

A SPC mesoscale crystalliser was assembled for characterisation of liquid and solid phase RTD (see Figure 2). The platform consisted of one L-shaped unjacketed $90^{\circ}$ glass bend (B90) and six jacketed SPC meso-tubes (S0 - S5) connected in series by five unjacketed Ushaped glass bends $(\mathrm{B} 0-\mathrm{B} 4)$ using PEEK connectors. The total volume and length of the crystalliser was $72 \mathrm{ml}$ and $5.4 \mathrm{~m}$ respectively. The first SPC meso-tube, forming the first section of the crystalliser, was $0.796 \mathrm{~m}$ in length, and was connected to the oscillator unit by the $90^{\circ}$ glass bend. The other five sections each consisted of $0.727 \mathrm{~m}$ long jacketed SPC mesotubes. The $90^{\circ}$ and U-shaped glass bends all had the SPC dimensions given in Figure 1. An important design feature of the U-shaped glass bend is that the right end of the bend has $10^{\circ}$ orientation to the horizontal plane. This gives each connected straight section a $10^{\circ}$ inclination, with the exit of the section higher than the entrance. This degree of inclination was determined by Reis et al. [3] as the optimal minimum angle for assembling a mesoscale OFR manufacturing unit, which comprises of multiple SPC meso-tubes connected in series. The optimum inclination is beneficial for minimising gas retention and facilitating bubble washout from the meso-tubes. 
Fluid oscillations in the SPC mesoscale crystalliser were achieved by a piston-driven diaphragm fixed at the bottom of a mixing chamber and connected to an electromagnetic oscillator (LDS, UK, V406). A signal generator (LDS, UK, PO100) and an amplifier (LDS, UK, PA100E) provided a range of oscillation amplitude and frequency of $x_{0}=0.5-3 \mathrm{~mm}$, $f=2-12 \mathrm{~Hz}$ for the system. Continuous steady flow was supplied by a Labhut Series 1500 dual piston pump, which fed the system with volumetric flow rates of up to $12 \mathrm{ml} \mathrm{min}^{-1}$.

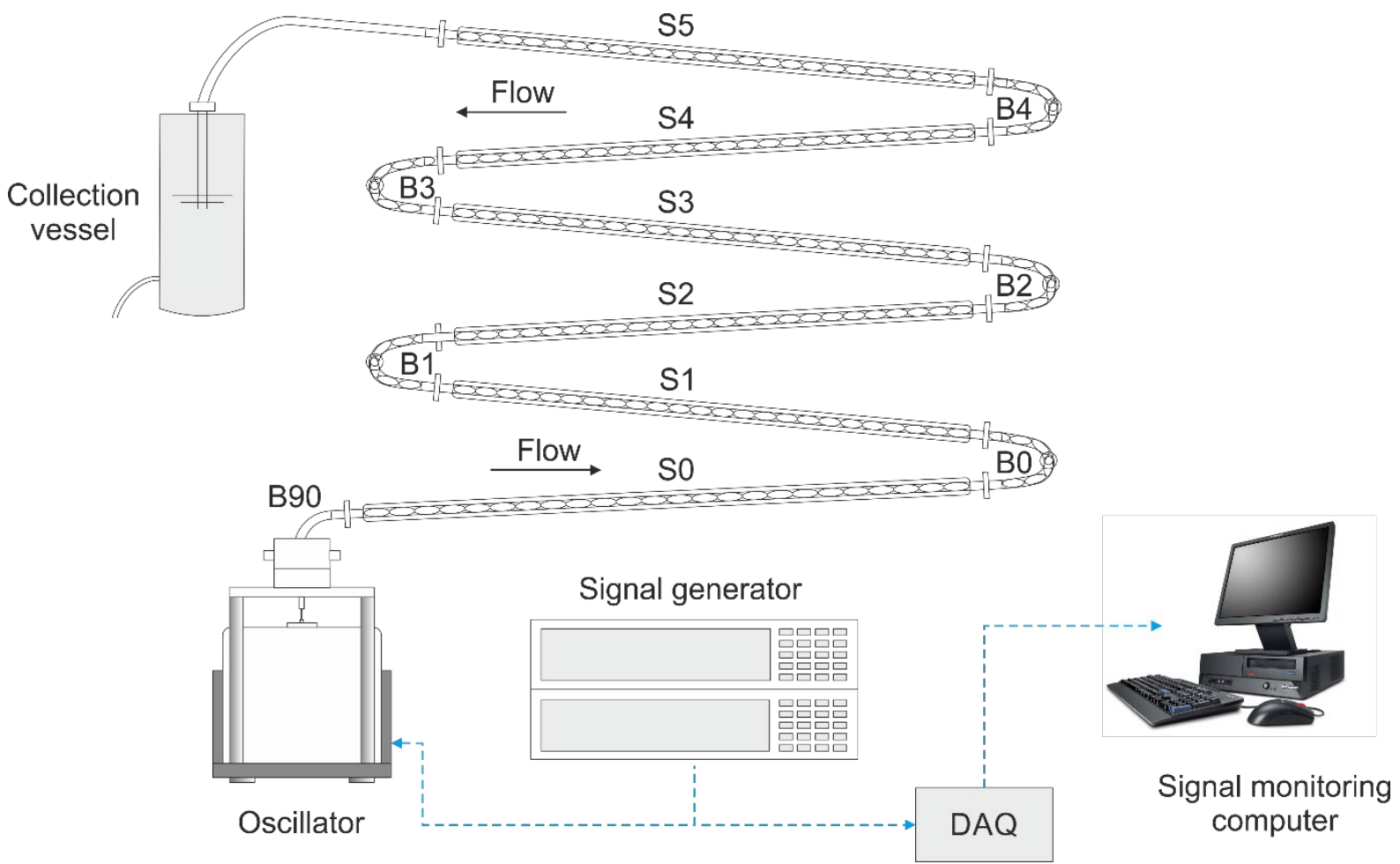

Figure 2 Schematic of the SPC mesoscale crystalliser platform (not drawn to scale).

\subsection{Non-invasive dual backlit imaging for liquid and solid RTD measurements}

Backlit imaging is a non-invasive technique that utilises a high-resolution camera to record images of objects that are suspended and transported in flow through a glass-walled tube, in this case the SPC meso-tube. Figure 3 shows a schematic for the dual backlit imaging technique developed for separate liquid and solid RTD measurements in the SPC mesoscale 
crystalliser. The setup consisted of dual measurement points (to provide upstream and downstream concentration profiles) along the SPC mesoscale crystalliser; with an air-filled opaque box enclosure constructed around each measurement point on an SPC meso-tube to exclude stray ambient light. At each measurement point, backlighting was provided by an ACpowered LED light source to give an even illumination and aid image visualisation in the SPC meso-tube. A high-definition webcam (Logitech ${ }^{\circledR}$ C920 HD Pro) with 1080p maximum resolution was placed $\sim 1 \mathrm{~cm}$ from SPC meso-tube wall to maximize the magnification of a single inter-constriction cavity. Both HD cameras were connected via USB 2.0 to a PC running YAWCAM 0.4.1 software which enabled simultaneous image capture and storage on a computer drive.

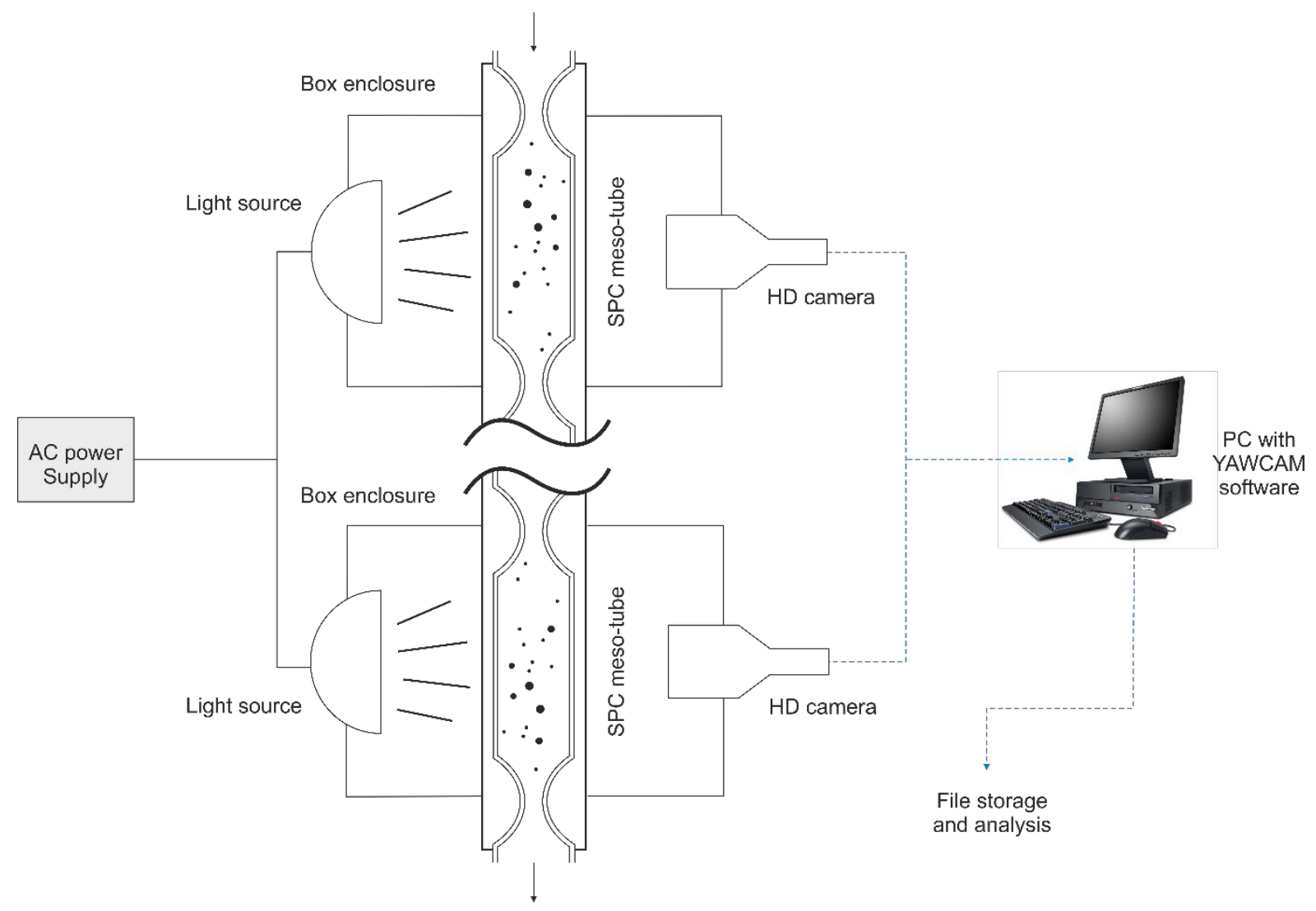

Figure 3 Schematic of data acquisition for dual backlit imaging technique. 


\subsubsection{Image analysis for concentration-time history}

The HD cameras were mounted at separate measurement points along the SPC mesoscale crystalliser to enable RTD determination by the imperfect pulse method (see section 2.6). For RTD measurements in the SPC mesoscale crystalliser, a pulse of coloured dye (or a slug of particles) is injected upstream of a first camera (Cam A), and flows past a second camera downstream (Cam B), experiencing a degree of axial dispersion. The images from each camera can be converted to give an input (Cam A) and output (Cam B) time history of the concentration of dye or particles, from which the liquid or solid phase RTD can be deduced. Figure 4 shows a sequence of grayscale images captured from the upstream camera (Cam A) for a solid RTD experiment using a $0.5 \mathrm{ml}$ slug injection containing $2 \mathrm{~g} \mathrm{ml}^{-1}(67 \% \mathrm{w} / \mathrm{w})$ of polystyrene particles with a $d_{50}$ of $70 \mu \mathrm{m}$. True colour images (RGB) from both HD cameras were converted to grayscale images by a script developed in MATLAB ${ }^{\circledR}$. Each grayscale image had an array of $480 \times 640$ pixels, and each pixel contained a numerical value for a grayscale intensity ranging from -128 (black) to +127 (white). All grayscale images were cropped into $250 \times 110$-pixel target images focused on a single backlit inter-constriction cavity as a region of interest (ROI) (see Figure 4), and an average grayscale intensity was calculated for each image. The background contained information about the camera noise and grayscale intensity observed for the clear liquid and glass wall only. The background was therefore taken as the baseline for normalisation. RTD information was extracted from recorded images in the form of absorbance-time curves. For liquid and solid phase studies, a slug of particles or pulse of coloured dye in water will effectively decrease the intensity of the transmitted beam to the camera in accordance with Beer-Lambert's law:

$$
I=I_{0} \exp \left(-\epsilon c l_{p}\right)
$$


where $\epsilon$ is the light-scattering cross-section of a particle or wavelength-dependent molar absorptivity coefficient $\left(\mathrm{M}^{-1} \mathrm{~cm}^{-1}\right), I$ is the intensity $\left(\mathrm{W} \mathrm{m}^{-2}\right)$ of light transmitted through the suspension or dye (measured intensity), $I_{0}$ is the incident light intensity $\left(\mathrm{W} \mathrm{m}^{-2}\right), c$ is the particle or dye concentration $\left(\mathrm{g} \mathrm{ml}^{-1}\right)$, and $l_{p}$ is the optical path length (m).
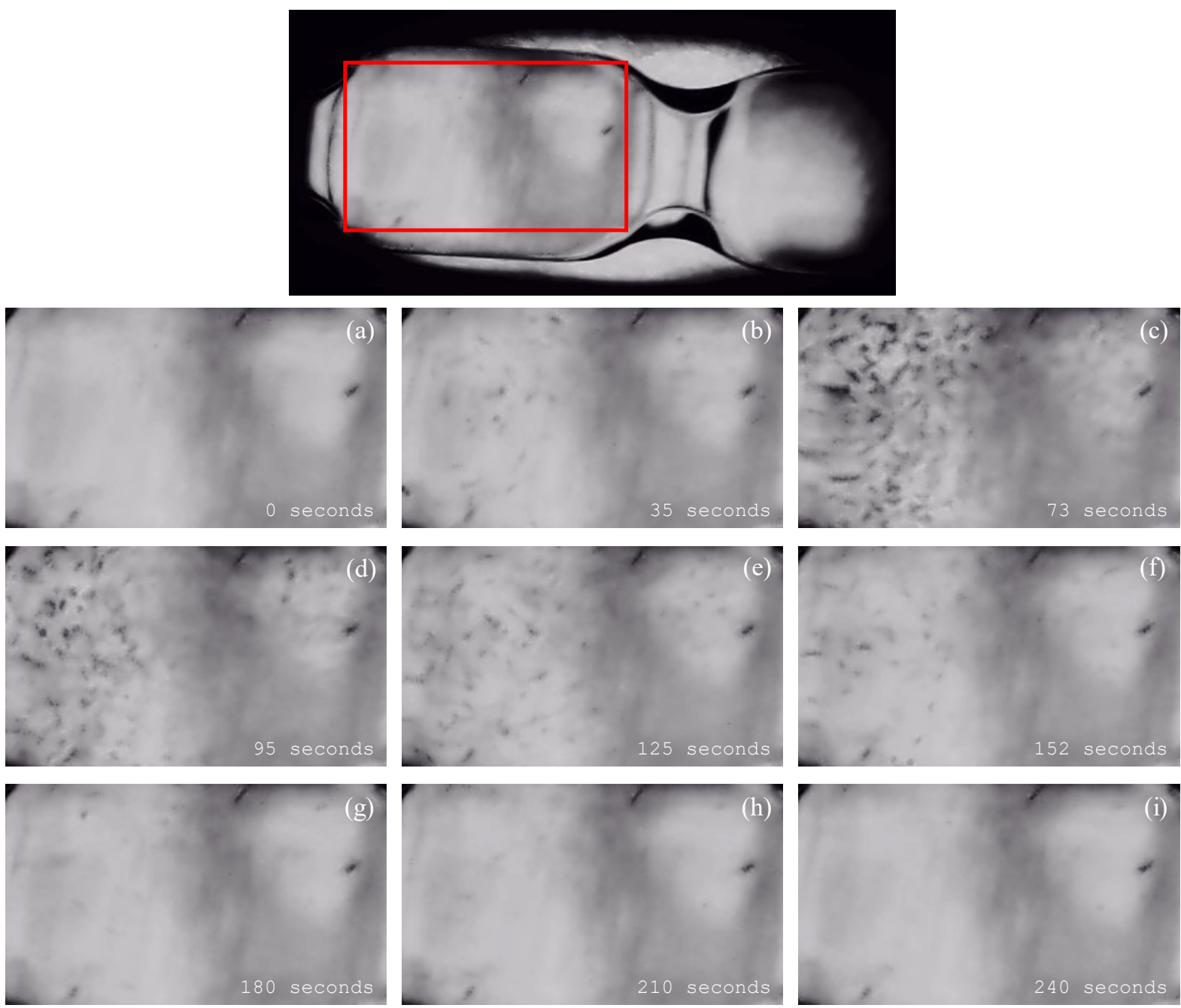

Figure 4 Top: Backlit SPC meso-tube captured from Cam A. Red rectangle indicates ROI from which grayscale intensities were calculated. Bottom: Enlarged images of the ROI. From (a) - (i): $t=0 \mathrm{~s}, 35 \mathrm{~s}, 73 \mathrm{~s}, 95 \mathrm{~s}, 125 \mathrm{~s}$, $152 \mathrm{~s} 180 \mathrm{~s}, 210 \mathrm{~s}, 240$ s. $x_{0}=0.5 \mathrm{~mm}, f=12 \mathrm{~Hz}, R e_{n}=21$.

Absorbance-time curves for the liquid and solid phase studies were calculated by taking the $\log$ of the grayscale intensity to be proportional to concentration according to Equation (6): 


$$
a b s=-\log \frac{I}{I_{0}}
$$

where $a b s$ is the absorbance of the species. Both HD webcams were pre-calibrated and returned a linear relationship between measured absorbance and concentration, with $R^{2}=0.9979$ for Cam A and 0.9949 for Cam B in the entire range of experiments (see Figure 5).

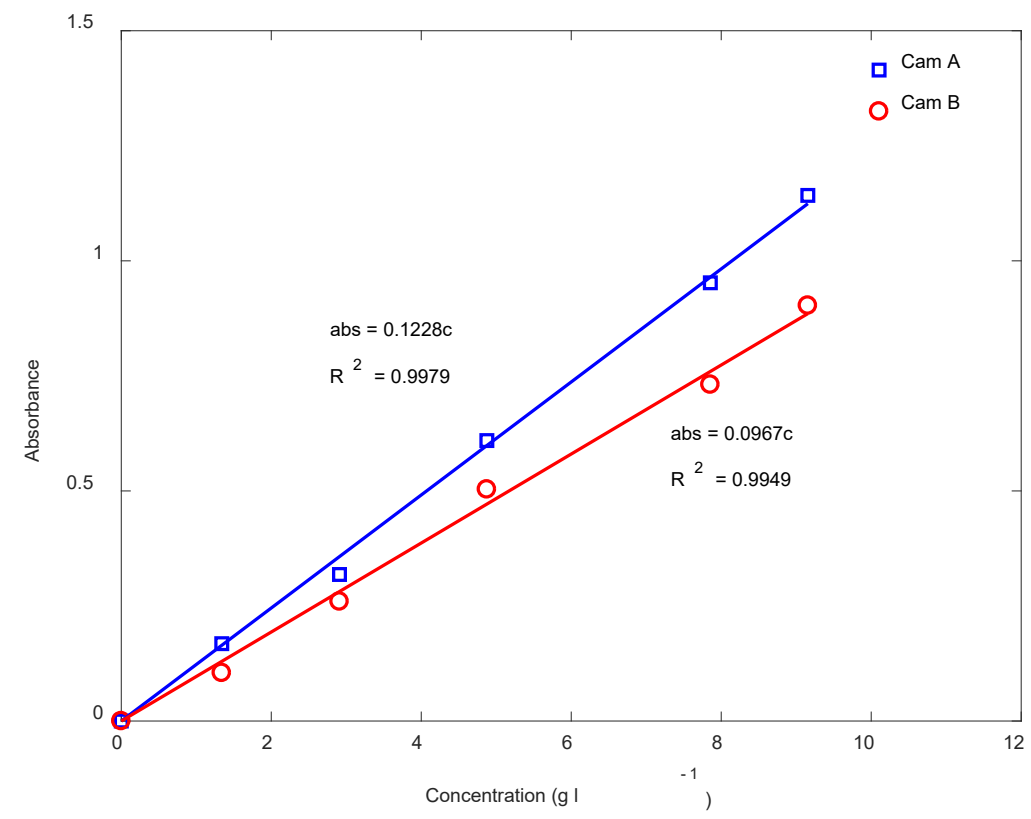

Figure 5 Linear relationship established between absorbance $(a b s)$ and concentration $(c)$ for Cam A and Cam B.

\subsection{Liquid phase RTD studies}

An aqueous solution of Procion Red HE-7B dye was used as the tracer for liquid phase RTD studies. This dye was selected as it did not adsorb onto the meso-tube walls. Degassed deionized water formed the continuous phase and was pumped at a steady net flow rate from a closed reservoir by a pulsation-free dual piston pump. Prior degassing of the continuous phase was necessary to avoid bubble nucleation and oscillation dampening in the SPC mesoscale crystalliser. The continuous phase was oscillated at the conditions $x_{0}=0.5,1.0,2.0 \mathrm{~mm}$ and 
$f=2,4,6,8,10,12 \mathrm{~Hz}$ giving an investigated mixing range of $R e_{o}=31-740$. Experiments

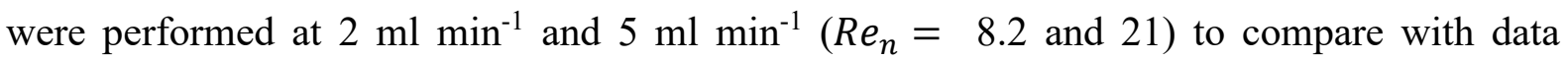
previously obtained by Zheng and Mackley [18] at similar net flow rates $\left(R e_{n}=10\right.$ and 19) for the same OFM device. These volumetric flow rates used corresponded to superficial axial velocities of $2.48 \times 10^{-3} \mathrm{~m} \mathrm{~s}^{-1}$ and $6.19 \times 10^{-3} \mathrm{~m} \mathrm{~s}^{-1}$ respectively in the SPC mesoscale crystalliser. For the SPC meso-tube in which the cross-sectional area varies, the superficial velocity, $u$, was determined for a mean internal diameter of $4.14 \mathrm{~mm}$. The mean internal diameter for an SPC meso-tube was calculated using Equation (7):

$$
D_{\text {mean }}=2 \sqrt{\frac{V_{S P C}}{\pi L_{S P C}}}
$$

where $V_{S P C}$ is the measured volume in an SPC meso-tube with a length, $L_{S P C}$, of $727 \mathrm{~mm}$. Cam A was mounted at measurement point 1, $0.490 \mathrm{~m}$ downstream of the tracer injection point (see Figure 6). Cam B was mounted at measurement point 2, located $3.181 \mathrm{~m}$ downstream of the injection point to give $L$ of $2.691 \mathrm{~m}$ (axial distance between measurement point 1 and 2), having a volume of $35 \mathrm{ml}$. All experiments were carried out at room temperature of $20{ }^{\circ} \mathrm{C}$. Before performing an experiment, it was ensured that the SPC mesoscale crystalliser was filled with water and completely bubble-free. Degassing of the system was achieved by operating at $x_{0} \geq$ $2 \mathrm{~mm}, f \leq 2 \mathrm{~Hz}$ to create a sweeping motion through the inter-constriction cavities. The $10^{\circ}$ inclination of the SPC mesoscale crystalliser aided bubble washout. At $t=0$ a pulse of $0.1 \mathrm{ml}$ containing $3.14 \mathrm{~g} \mathrm{l}^{-1}$ of dye was injected by hand into the tracer injection port in $<1 \mathrm{~s}$ using a $1 \mathrm{ml}$ syringe. Both HD cameras started image capture simultaneously at a $1 \mathrm{~s}$ interval and were stopped once transmittance visibly returned to background level. A lag time of $0.12 \mathrm{~s}$ was detected and corrected for in the analysis. This lag time was due to a delay between image 
capture by the HD cameras and storage of .jpg files on the local drive by the YAWCAM software.

Different dye tracer concentrations were tested initially, however lower concentrations were quickly dispersed and too dilute to be detected by the HD cameras. Very high concentrations were too dense, causing excessive tailing in the concentration profiles. An intermediate dye tracer concentration with a density closer to water $\left(1.003 \mathrm{~g} \mathrm{~cm}^{-3}\right)$ which was detectable by both HD cameras was finally chosen for experiments. Both HD cameras started image capture simultaneously at $1 \mathrm{~s}$ intervals and were stopped once transmittance visibly returned to background level. All experiments were performed at least in duplicate.

\subsubsection{Dual backlit imaging technique versus traditional conductivity measurement}

Salt tracer experiments were performed to compare the dual backlit imaging technique against the traditional intrusive conductivity measurement for liquid RTD determination. The evaluation criteria were the values of hydrodynamic parameters obtained by both methods i.e. axial dispersion number, $D_{a x} / u L$, mean residence time, $\tau$, and mean axial velocity, $u$, as well as the reproducibility of each method for replicated experiments.

For salt tracer injection and response experiments, a pair of calibrated Mettler Toledo $\mathrm{InLab}^{\circledR} 751-4 \mathrm{~mm}$ conductivity probes (2-pole platinum micro conductivity cell) were positioned $2.691 \mathrm{~m}$ apart and immersed perpendicular to the flow in the sample ports located at the U-shaped glass bends (see Figure 6). The calibration curve for both probes showed a linear relationship with molarity (see Figure 7). All experiments were carried out at a room temperature of $20{ }^{\circ} \mathrm{C}$ and a net flow rate of $5 \mathrm{ml} \mathrm{min}^{-1}\left(R e_{n}=21\right)$. The range of frequencies investigated was $f=2-12 \mathrm{~Hz}$ at a fixed $x_{0}$ of $0.5 \mathrm{~mm}$. At $t=0$, a pulse of $0.2 \mathrm{ml}$ containing $0.05 \mathrm{M} \mathrm{NaCl}$ with a density of $0.9994 \mathrm{~g} \mathrm{~cm}^{-3}$ was injected by hand into the tracer injection port 
(see Figure 6) in $<1 \mathrm{~s}$ using a $1 \mathrm{ml}$ syringe. A conductivity meter connected to both probes recorded data at a $1 \mathrm{~s}$ interval and was stopped once the conductivity reading returned to background level. The response time of both probes to the conductivity meter was instantaneous. All experiments were performed at least in duplicate for both methods.

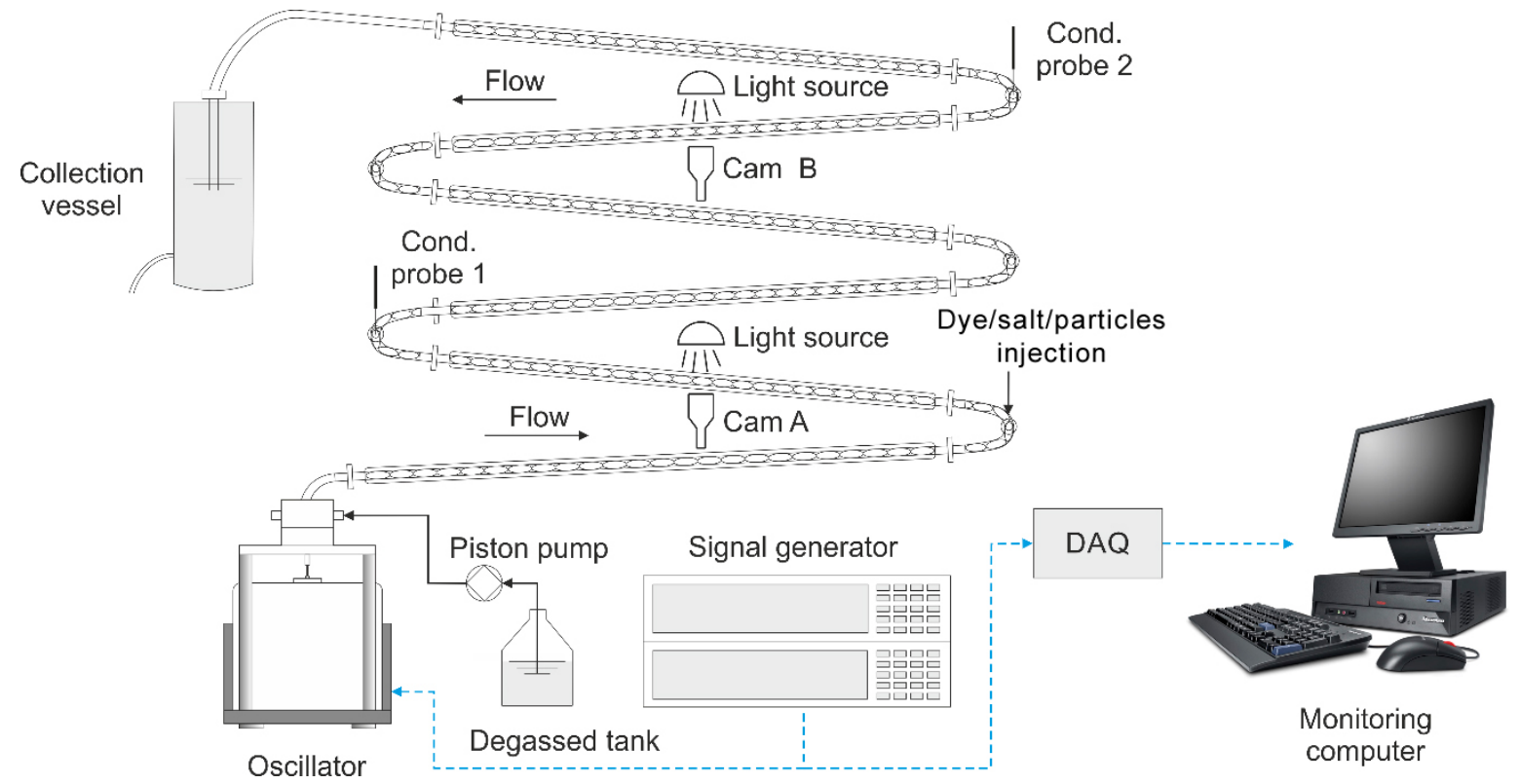

Figure 6 Experimental set-up for RTD measurements in the SPC mesoscale crystalliser using the dual backlit imaging technique and traditional conductivity measurements (not drawn to scale). 


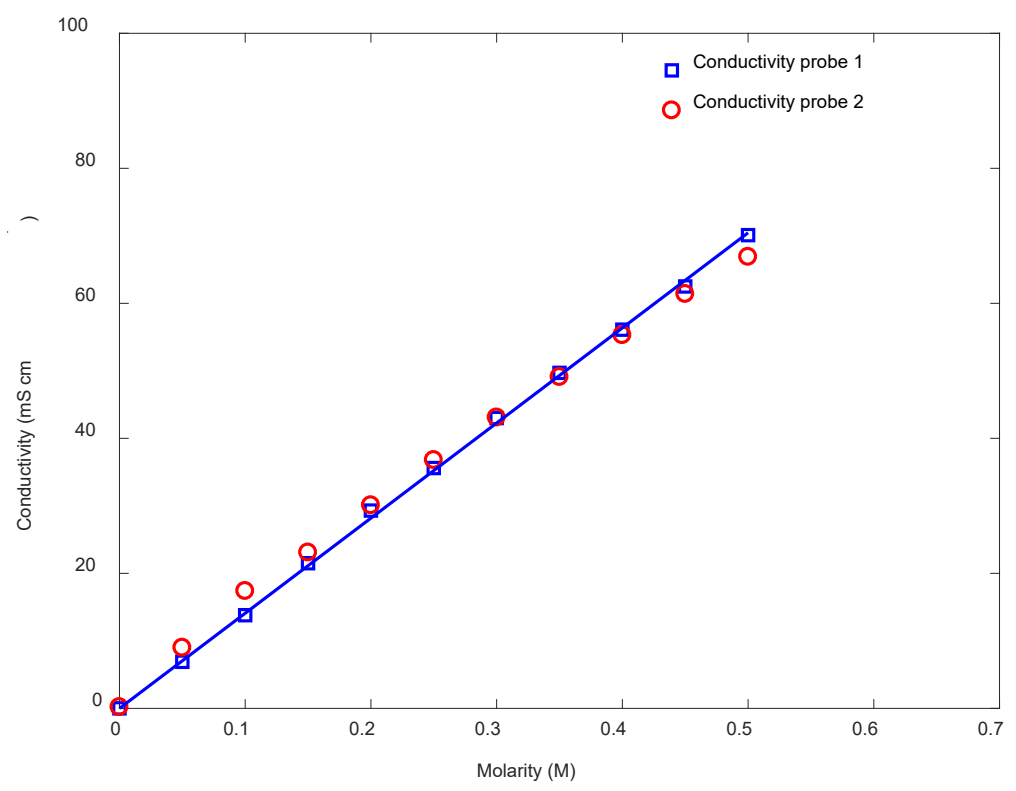

Figure 7 Linear relationship established between conductivity and molarity for both conductivity probes.

\subsection{Solid phase RTD studies}

Polystyrene particles were chosen to mimic the particle flow characteristics of paracetamol crystals, since sticky paracetamol crystals repeatedly adhered to the meso-tube walls, causing multi-modal $C$-curves. Polystyrene particles have a particle density $\left(\rho_{p}=1.1 \mathrm{~g}\right.$ $\left.\mathrm{cm}^{-3}\right)$ which is close to that of paracetamol crystals $\left(\rho_{c}=1.26 \mathrm{~g} \mathrm{~cm}^{-3}\right)$. Also, a particle $d_{50}$ of $70 \mu \mathrm{m}$ was not far off from the typical mean size of paracetamol crystals obtained from cooling crystallisation processes $[24,25]$. A $0.5 \mathrm{ml}$ slug containing a $2 \mathrm{~g} \mathrm{ml}^{-1}(67 \% \mathrm{w} / \mathrm{w})$ aqueous suspension of polystyrene particles was injected at $t=0$ in $<1 \mathrm{~s}$ through the tracer injection port to mimic a stream of particles flowing through the SPC mesoscale crystalliser. Figure 8 shows the spherical nature of the polystyrene particles. The maximum steady-state settling velocity, $u_{p}$, of the polystyrene particles was calculated as $0.0044 \mathrm{~m} \mathrm{~s}^{-1}$ using Equation (8):

$$
u_{p}=\sqrt{\frac{4}{3} \frac{1}{C_{D}} g d_{p}\left(\frac{\rho_{p}-\rho}{\rho_{p}}\right)}
$$


where $\rho_{p}$ is the density of the particles $\left(\mathrm{kg} \mathrm{m}^{-3}\right), \rho$ is the density of the bulk fluid $\left(\mathrm{kg} \mathrm{m}^{-3}\right), g$ is the acceleration due to gravity $\left(\mathrm{m} \mathrm{s}^{-2}\right), d_{p}$ is the mean diameter of the particles $(\mathrm{m})$, and $C_{D}$ is the drag coefficient, which has a value of 2.48 at $R e_{n}=21$ [26]. The oscillatory range investigated was determined from the results of liquid phase RTD measurements. Cam A and Cam B were used for image capture at $1 \mathrm{~s}$ intervals and stopped once transmittance returned to its background value. All experiments were performed at least in duplicate, and at room temperature of $20^{\circ} \mathrm{C}$.

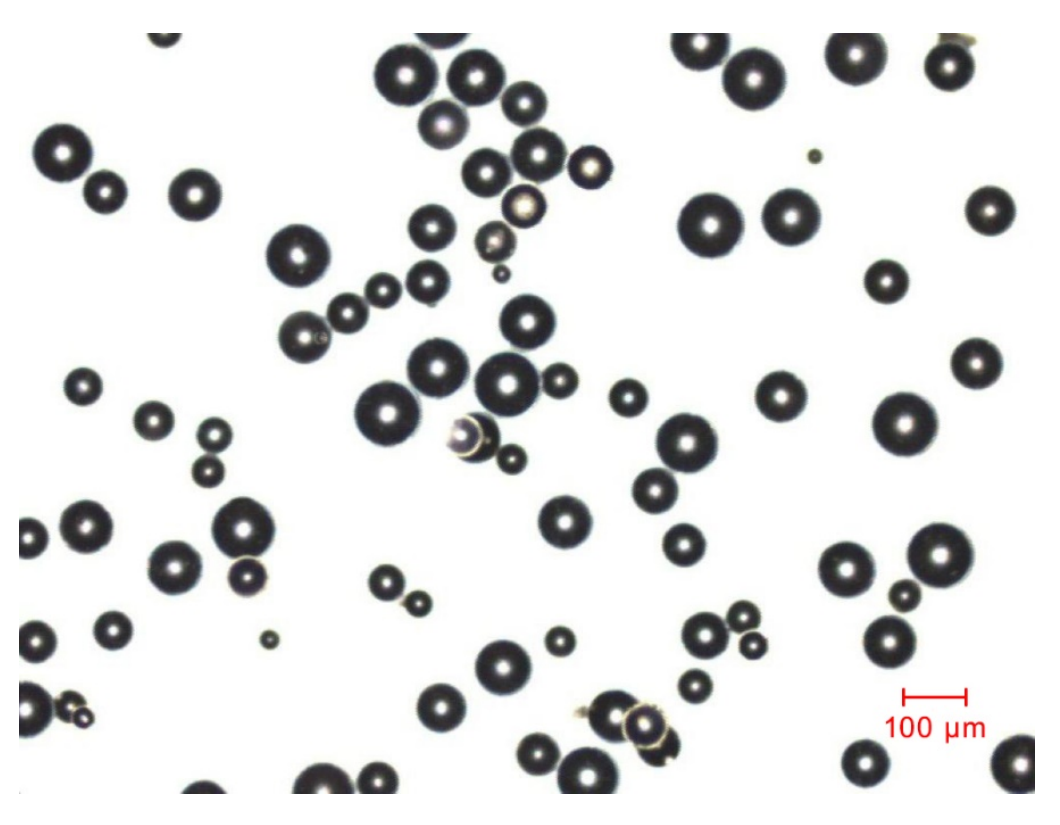

Figure 8 Microscope image of the spherical polystyrene particles used for solid phase RTD studies. Particles have a $d_{50}$ of $70 \mu \mathrm{m}$.

\subsection{Determination of axial dispersion coefficient}

All experimental data were fitted with an axial dispersion model [27]. This model was chosen for its capability to capture the intermediate backmixing state expected for the constricted SPC mesoscale crystalliser when operated at different oscillatory flow conditions 
[14]. It is therefore suitable for describing the degree of deviation of the SPC mesoscale crystalliser from true plug flow behaviour. In the imperfect pulse method of the axial dispersion model [28], a tracer is introduced into the flow and a pair of measurement devices (i.e. HD cameras or conductivity probes) detect the upstream and downstream concentration-time history ( $C$-curve) of a tracer, since the input tracer pulse may be far from a perfect Dirac delta function [29] which is very difficult to achieve experimentally. In the section between the two measurement devices, the tracer is further dispersed, so that the concentration-time history detected by the downstream probe is time-shifted and distorted, compared to that detected by the upstream measurement device. For a fixed distance between the upstream and downstream measurement point, the amount of spreading depends on the intensity of dispersion in the system, and this spread can be used to characterise quantitatively the dispersion phenomenon. The imperfect pulse method effectively convolutes the input function from the upstream probe with an axial dispersion model and fits the response to the downstream output function by adjusting the model parameters. The benefit of this method is that any input signal shape can be used.

In this analysis it is assumed that the axial dispersion model may be applied to any section of a flow to estimate the local liquid or solid dispersion coefficient. The axial dispersion model describes the mixing behaviour by superimposing one-dimensional axial dispersion onto convective plug flow. The effect of any radial velocity gradients is lumped into the axial dispersion coefficient, as demonstrated by Taylor [30]. In dimensionless form, the axial dispersion model is represented by the following differential equation:

$$
\frac{\partial C^{*}}{\partial \theta}=\left(\frac{D_{a x}}{u L}\right) \frac{\partial^{2} C^{*}}{\partial z^{2}}-\frac{\partial C^{*}}{\partial z}
$$

where $C^{*}=\frac{\left(C-C_{i}\right)}{\int_{0}^{\infty}\left(C-C_{i}\right) d t}=$ dimensionless concentration for tracer 


$$
\begin{aligned}
& z=\frac{x}{L}=\text { dimensionless length } \\
& \theta=\frac{t}{\tau}=\text { dimensionless time }
\end{aligned}
$$

$\tau$ is the characteristic time or mean residence time in the test section under consideration. $C_{i}$ is the initial concentration of species $\left(\mathrm{g}^{-1}\right)$ and $C$ is the concentration at any measured time $t(\mathrm{~s})$. $u$ is the mean axial velocity $\left(\mathrm{m} \mathrm{s}^{-1}\right), x$ is the position along the axial length $(\mathrm{m}), L$ is the length of the test section (m). For the pulse experiment employed, the usual normalisation is to set the initial baseline value to zero and then to divide by the integral of the concentration. The estimates of the degree of liquid and solid backmixing are so described by the dimensionless axial dispersion number, $D_{a x} / u L$, and a convective time scale:

$$
\tau=L / u
$$

The dispersion number characterises axial dispersion as the liquid or solid circulates once through the section in terms of an effective dispersion coefficient, $D_{a x}\left(\mathrm{~m}^{2} \mathrm{~s}^{-1}\right)$. This parameter represents axial dispersion in an analogous manner to the way in which molecular diffusivity, as used in Fick's law, represents molecular transport. The value of the dispersion number expresses the degree of axial mixing; if the dispersion number approaches zero, the region's mixing behaviour is close to plug flow, whereas, for large dispersion numbers, the zone is well-mixed. According to Levenspiel [29], a $D_{a x} / u L>0.01$ indicates a large deviation from plug flow, while $D_{a x} / u L<0.01$ indicates a small deviation from plug flow.

The solution of Equation (9) depends on the boundary conditions at the inlet and outlet of the fluid section. The open-open boundary condition corresponds most closely to the 
experimental situation here. This means that there is continuity of both the tracer flux and concentration profiles across the boundaries (marked by the position of the measurement devices), which from a physical point of view, is a valid assumption. An advantage of the axial dispersion model is that subject to open-open boundary conditions, it can be solved analytically. The solution of Equation (9), for an initial Dirac delta function and with openopen boundary conditions, was obtained by Levenspiel and Smith [27]:

$$
C^{*}(\theta)=\frac{1}{\sqrt{4 \pi\left(D_{a x} / u L\right)}} \exp \left[-\frac{(1-\theta)^{2}}{4 \theta\left(D_{a x} / u L\right)}\right]
$$

To study liquid and solid phase dispersion in an individual section of the flow, the imperfect pulse technique is applied, whereby data sets taken from two measuring points a fixed distance, $L$, apart are compared, and the input signal initial shape is arbitrary. For a linear system, the output response, $C_{1}^{*}(\theta)$, can be determined from the convolution integral of the inlet, $C_{0}^{*}(\theta)$, and the system transfer function, $M(\theta)$ :

$$
C_{1}^{*}(\theta)=\int_{0}^{\infty} M(\theta) C_{0}^{*}\left(\theta-\theta^{\prime}\right) d \theta
$$

Using $M(\theta)$, an output signal can be predicted for any arbitrary continuous input signal. The system transfer function is the response to a Dirac pulse; in the case of the axial dispersion model, $M(\theta)$ is given by Equation (14). The results of the convolution integral can then be fitted to the measured output concentration-time history, by adjusting the two model parameters $\tau$ and $D_{a x} / u L$. Once the best-fit parameters have been found, $D_{a x}$ may be calculated using Equations (16) and (17): 


$$
\begin{aligned}
& u=\frac{L}{\tau} \\
& D_{a x}=\left(\frac{D_{a x}}{u L}\right) \frac{L^{2}}{\tau}
\end{aligned}
$$

Previous work by Palma and Giudici [31] has shown that fitting more than one model parameter gives values of axial dispersion coefficient that are more reliable than when $D_{a x}$ is the only fitted parameter.

\subsection{Parameter estimation method}

Hydrodynamic parameter estimation was performed by convoluting in the frequency domain and fitting in the time domain, since it gives nearly the same accuracy as time domain convolution [32,33]. Also, complex numerical calculations can efficiently be performed computationally using Discrete Fourier transformation (DFT). An algorithm of the method is provided in Figure 9, where an overbar denotes a Fourier transform in the frequency space, $\omega$. After the tracer input signal has been normalised to give $C_{0}^{*}(\theta)$, its Fourier transform is calculated using the Fast Fourier Transformation (FFT) method which is a form of DFT. The model output concentration is then obtained by multiplying, in the frequency domain, the model transfer function and the experimental input concentration. According to the convolution theorem, the result of this product in the frequency domain is the Fourier transform of the convolution integral:

$$
\int_{-\infty}^{\infty} M(\theta) C_{0}^{*}\left(\theta-\theta^{\prime}\right) d \theta \Leftrightarrow \overline{C_{0}^{*}}(\omega) \bar{M}(\omega)
$$


where $\Leftrightarrow$ denotes a transform pair. The calculated output concentration is then converted back into the time domain by inverse Fourier transformation (inverse FFT); it is subsequently fitted, in the time domain, to the measured output, by adjusting the characteristic time, $\tau$, and the dispersion number, $D_{a x} / u L$, in the transfer function. The optimum $D_{a x} / u L, \tau$ combination is that which minimises the residual sum of squares (RSS) between model and experiment.

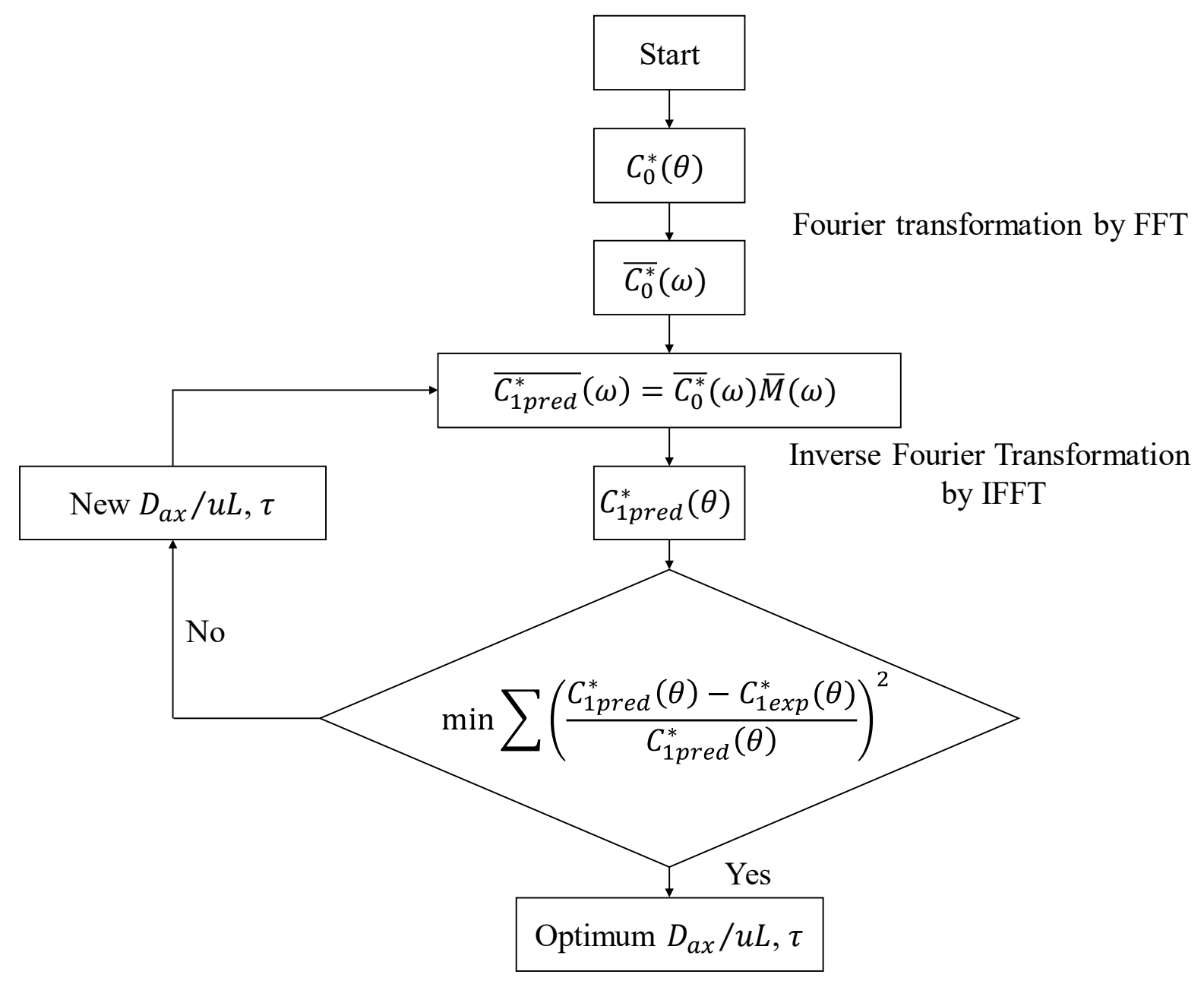

Figure 9 Algorithm for the parameter estimation method with convolution in the frequency domain and fitting in the time domain. Adapted from Obradovic et al. [33]. 


\section{Results and discussion}

\subsection{Axial dispersion from dual backlit imaging versus conductivity measurements}

A typical normalised input, output, and corresponding fitted response curve obtained from dual backlit imaging is shown in Figure 10 for an $R e_{o}$ of $308\left(x_{0}=1 \mathrm{~mm}, f=10 \mathrm{~Hz}\right)$

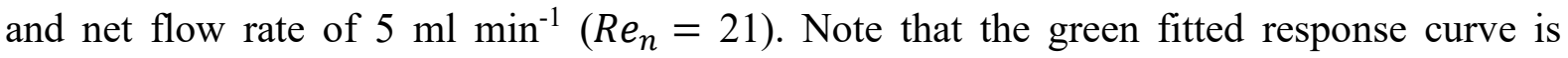
completely overlaid on the red output curve, showing a high quality of fit.

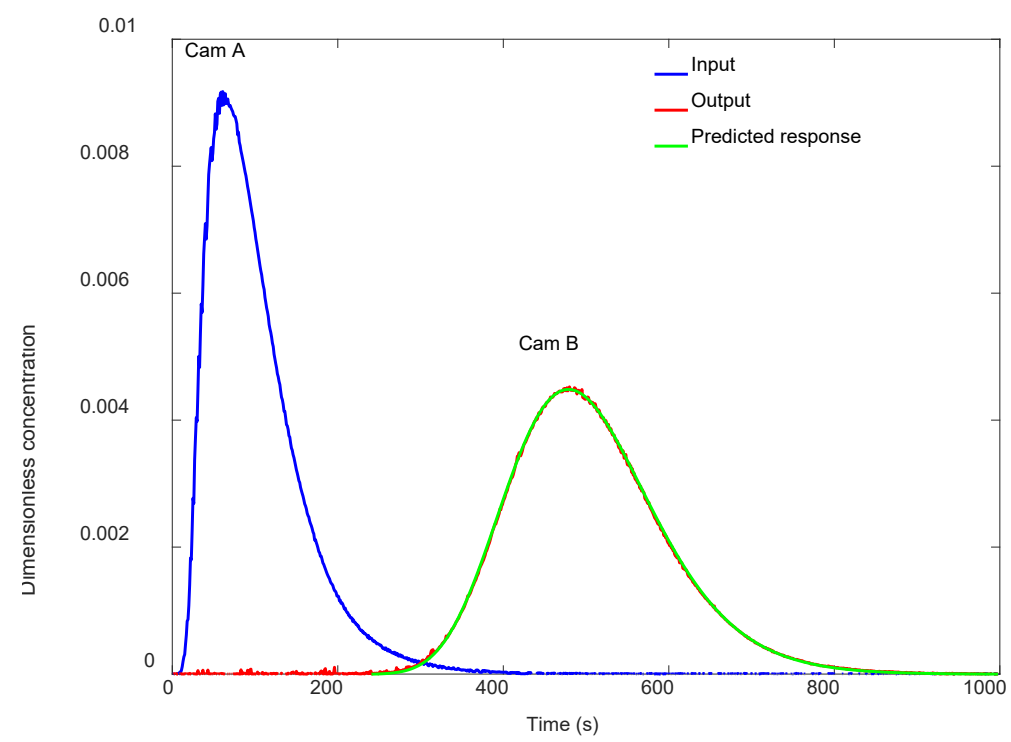

Figure 10 A normalised input (blue), output (red), and corresponding fitted response curve (green) from a dye tracer dual backlit imaging measurement. $R e_{n}=21, R e_{o}=308, S t=0.4, D_{a x} / u L=0.0135$.

Figure 11 and Figure 13 show the normalised input and output curves obtained from salt tracer conductivity measurements and dual backlit imaging measurements, respectively, for oscillatory conditions $R e_{o}=31-185$ at $R e_{n}=21$. Both methods detected a narrowing of liquid RTD with increasing $f$, and displayed a similar trend for $D_{a x} / u L$ (see Figure 12). Interestingly, the $C$-curves from intrusive conductivity measurements were significantly 
broader than those obtained from non-intrusive dual backlit imaging measurements. To investigate this further, a comparison of the hydrodynamic parameters for the two methods was carried out. The salt tracer in conductivity measurements was found to have an experimental $\tau$ of $455 \pm 14 \mathrm{~s}$ and mean superficial velocity, $u$, of $5.6 \times 10^{-3} \mathrm{~m} \mathrm{~s}^{-1}$. The dye tracer in dual backlit imaging measurements had an experimental $\tau$ of $443 \pm 12 \mathrm{~s}$ and $u$ of $5.9 \times 10^{-3} \mathrm{~m} \mathrm{~s}^{-1}$. Despite the close matching values for $\tau$ and $u$ for both measurement methods, $D_{a x} / u L$ values obtained from the non-intrusive imaging technique were much lower for the same $L$ and $R e_{n}$, and fell well within the plug flow region at $R e_{o}>93$ (see Figure 12). Also, at $R e_{o}<93$, there were large variations in $D_{a x} / u L$ values obtained from intrusive conductivity measurements.

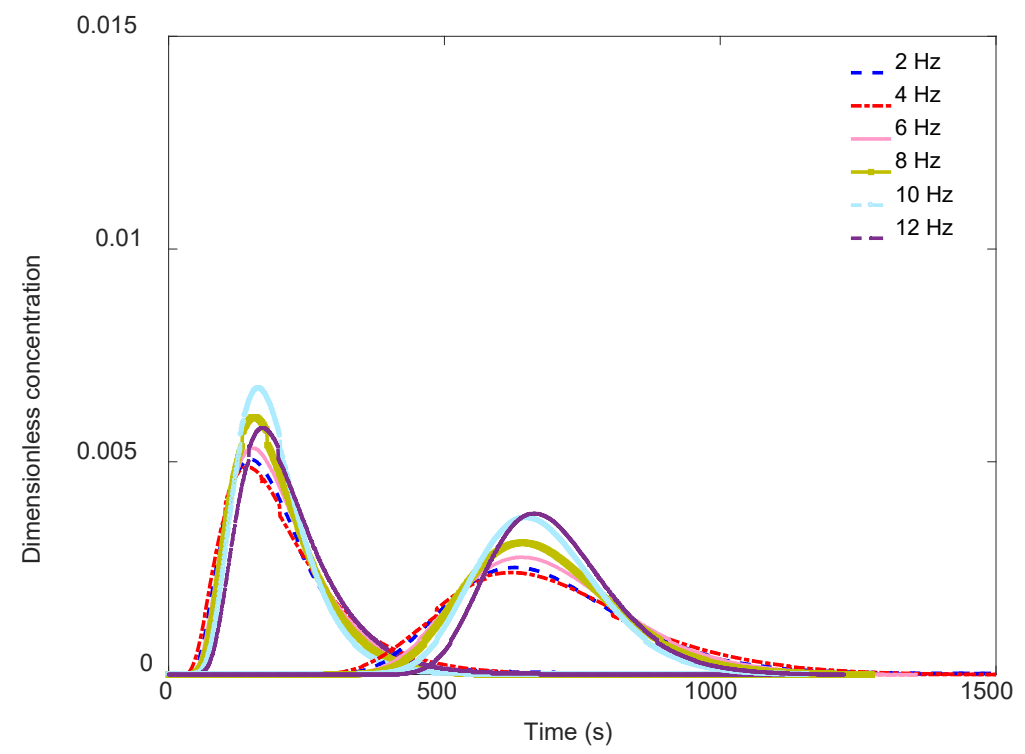

Figure 11 Normalised input and output curves from salt tracer conductivity measurements. $R e_{n}=21, R e_{o}=31$ -185, St $=0.8$.

Higher $D_{a x} / u L$ values were the result of significantly broader RTD curves obtained from intrusive conductivity measurements. A possible explanation for broader curves could be a delay in signal detection at the conductivity cells. This may be caused by (i) presence of localised dead zones in the small volume between the electrodes, or (ii) repeated salt deposition on the surface of electrodes, which would decrease sensitivity to concentration changes over 
time. In this way, measurements could be inaccurate. Issues with conductivity measurements have previously been reported by Fitch and Ni [34], where mass transfer problems were experienced. In contrast, the pixel-based measurements of the dual backlit imaging technique are highly sensitive to changes in transmitted light, making it possible to capture concentration changes in the meso-tube without delay. This enables reliable determination of hydrodynamic parameters.

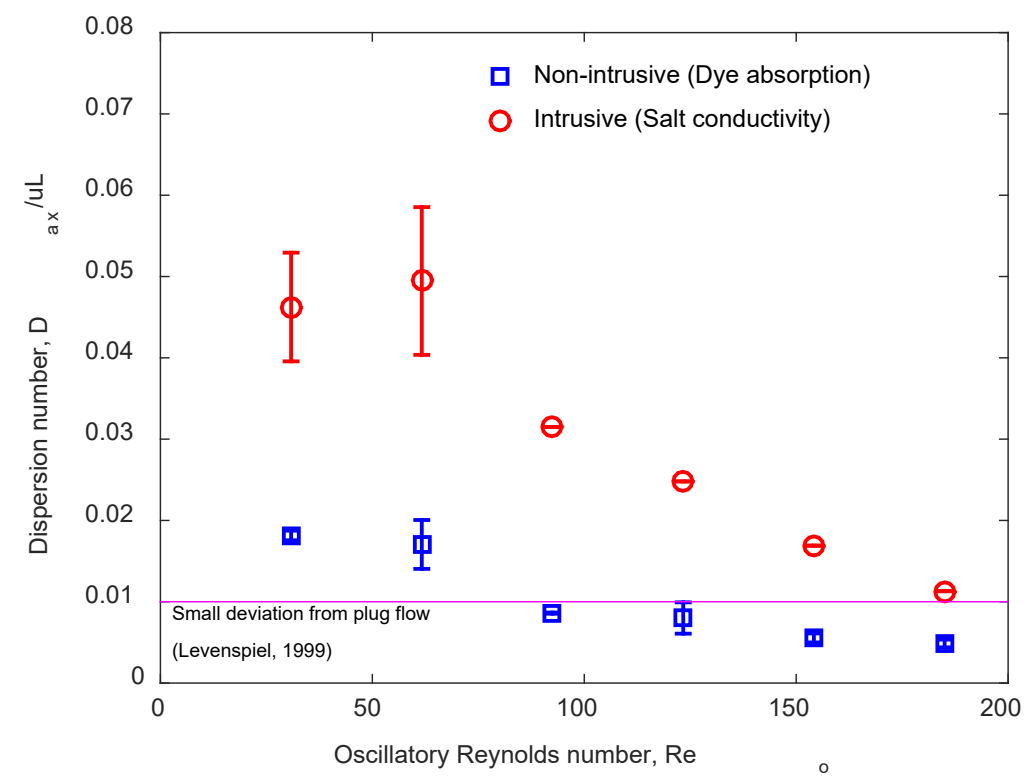

Figure 12 Comparison of $D_{a x} / u L$ values obtained from conductivity measurements and dual backlit imaging technique. $R e_{n}=21, L=2.691 \mathrm{~m}, S t=0.8$.

The dual backlit imaging technique offers non-disturbance of the fluid flow and the avoidance of probe fouling, both of which are commonly experienced with invasive measurements [34,35]. Additionally, the technique can be used for solid RTD measurements as demonstrated herein, whereas conductivity measurements are limited for such application. Intrusive spectroscopic techniques have been employed as alternatives to conductivity measurements for liquid RTD determination. Optical probes were used by Reis et al. [13] and Zheng and Mackley [18] to determine the mixing performance of SPC mesoscale OFRs. 
Siddique et al. [36] utilised a UV transflectance probe for RTD characterisation of a $69 \mathrm{~mm}$ i.d. COBC. More recently, Liu et al. [37] utilised in-situ Fourier transform infrared (FTIR) spectroscopy to characterise the RTD of a dynamic baffle OBR.

\subsection{Liquid phase RTD studies}

Experimental $C$-curves for over sixty experiments were derived from dye absorption measurements, and the effects of $R e_{o}, R e_{n}$, and $S t$ on the liquid phase axial dispersion performance were investigated. Figure 13 shows the normalised input and output curves and corresponding model response $M(\theta)$ obtained from dye tracer measurements over the range of oscillations $R e_{o}=31-185(S t=0.8, f=2-12 \mathrm{~Hz})$. On increasing $f$, the output curves showed less broadening, indicating a reduction in the spread of the tracer within the test section. This is easier to observe in the $M(\theta)$ curves which are unaffected by different pulse input shapes, as they are calculated response curves for a Dirac pulse input. $M(\theta)$ curves were calculated by the axial dispersion model using the estimated $D_{a x} / u L$ and $\tau$ as inputs. 


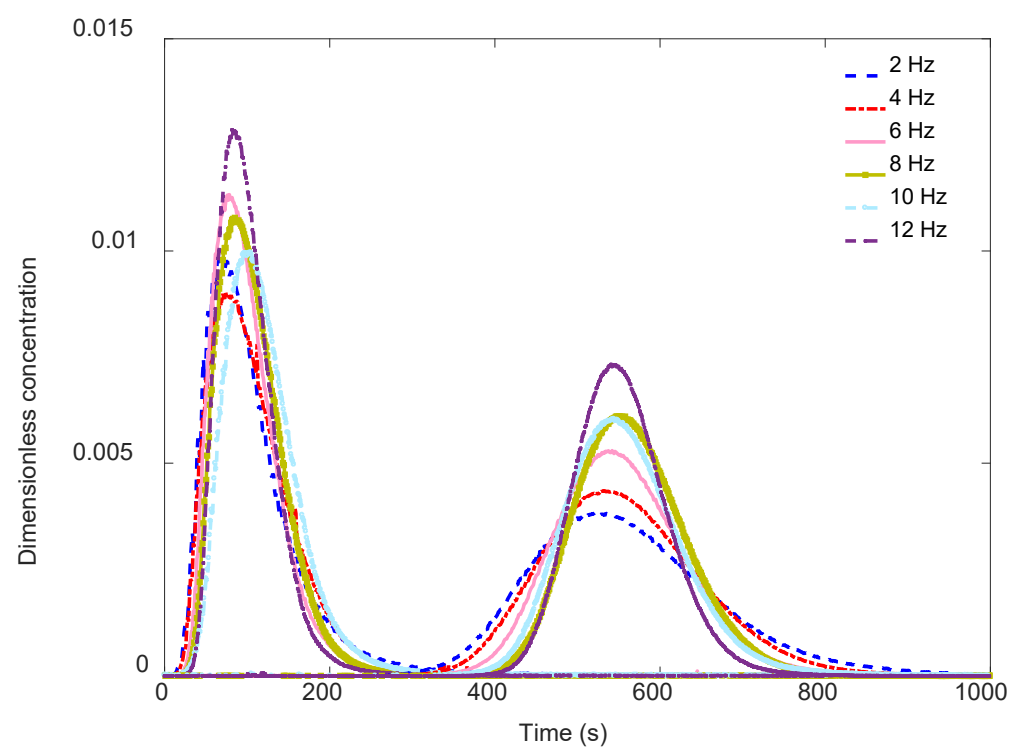

(b)

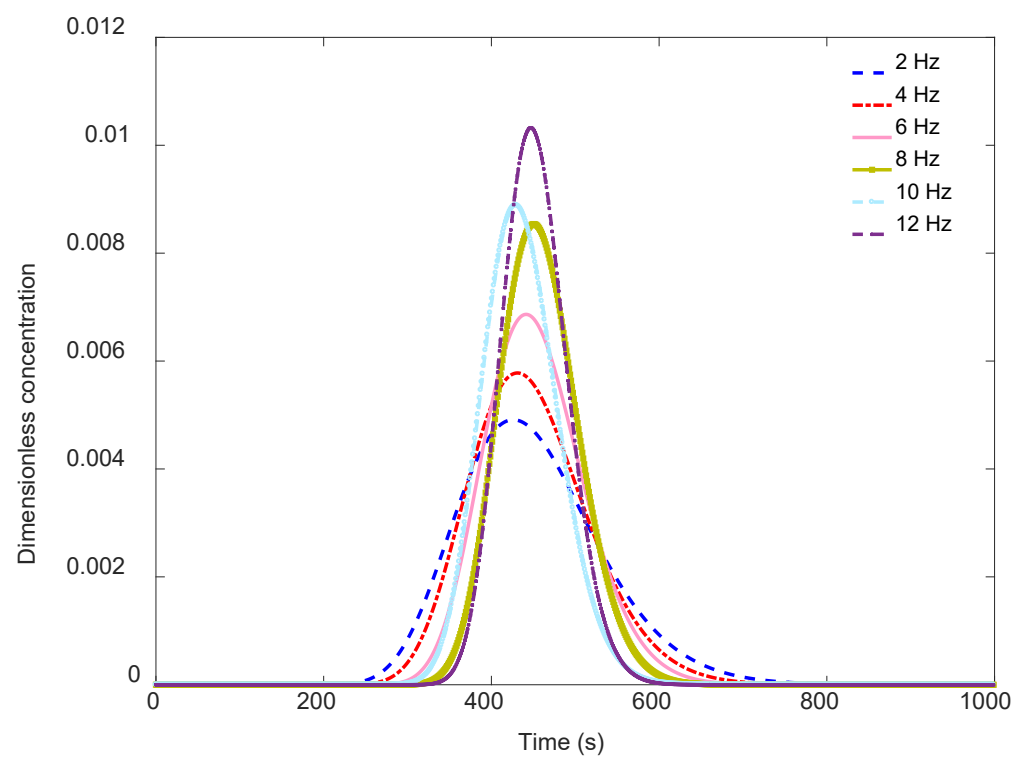

Figure 13 (a) Normalised input and output curves from dye tracer dual backlit imaging measurements (b) Model response, $M(\theta)$, for the liquid phase. $R e_{n}=21, R e_{o}=31-185, S t=0.8$.

Figure 14 summarises the experimental mean residence times, $\tau$, of the dye tracer for different oscillation conditions at $R e_{n}$ of 21 . At an average value of $442 \pm 11 \mathrm{~s}$, it was concluded that $\tau$ remains approximately constant and is unaffected by oscillatory conditions. A similar behaviour was observed by Phan and Harvey [20] and Reis et al. [14] in mesoscale OFRs. The flow rate used corresponds to a hydraulic time $(V / Q)$ of ca. $421 \mathrm{~s}$ in the test section, which is $5 \%$ shorter than the average experimentally determined $\tau$ for the tracer. This difference is within the range observed in other mesoscale OFRs. Reis et al. [13] found the 
hydraulic time in a $4.4 \mathrm{~mm}$ i.d. SPC mesoscale OFR to be $32.5 \%$ lower than the average $\tau$ at a flow rate of $1.94 \mathrm{ml} \mathrm{min}^{-1}$. Phan and Harvey [20] found an $8.5 \%$ difference between the average $\tau$ and the hydraulic time at an $R e_{n}$ of 7.2. Cruz et al. [16] found a $3-6 \%$ deviation between the hydraulic time and average $\tau$ in three planar mesoscale OFCs. A value of $\tau \gg$ hydraulic time would suggest that the tracer is delayed within the test section, indicating the presence of dead zones. The average superficial velocity, $u=L / \tau$, for all oscillatory conditions was experimentally determined as $6.0 \times 10^{-3} \pm 0.0002 \mathrm{~m} \mathrm{~s}^{-1}$, which corresponded to a volumetric flow rate of $5 \mathrm{ml} \mathrm{min}$. For experiments performed at $2 \mathrm{ml} \mathrm{min}^{-1}$, the average superficial velocity was experimentally determined to be $2.7 \times 10^{-3} \pm 0.0001 \mathrm{~m} \mathrm{~s}^{-1}$. These values are in agreement with superficial liquid velocities obtained by Reis et al. [14] in a $4.4 \mathrm{~mm}$ i.d. SPC mesoscale OFR.

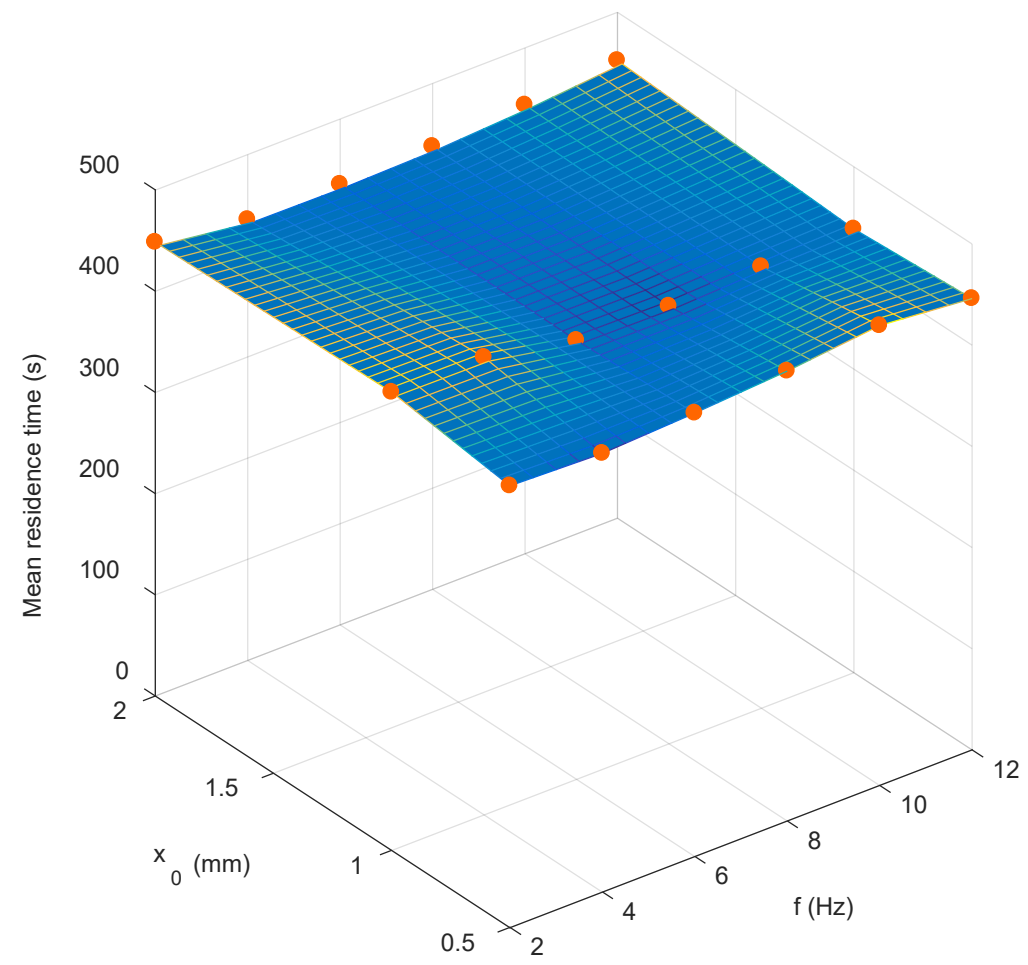

Figure 14 Average mean residence time of dye tracer for values of $x_{0}$ and $f$, for $R e_{n}=21$. 
Figure 15 shows the effect of net flow rate on $D_{a x} / u L$. At higher $R e_{n}, D_{a x} / u L$ decreased across the range of $R e_{o}$ investigated. This confirms that increasing net flow improves the overall RTD performance in the SPC mesoscale crystalliser by contributing to flow separation [38]. This is in agreement with findings by Zheng and Mackley [18] for the same mesoscale OFM device. Mohd Rasdi et al. [39] also found a positive effect of net flow rate on $n$ in a $5 \mathrm{~mm}$ i.d. SPC mesoscale OFR. Increasing $R e_{n}$ to 21 provided greater reductions in $D_{a x} / u L$ at $R e_{o}<100$; however, beyond $R e_{o}$ of 100 the differences in $D_{a x} / u L$ values for both net flow rates were much smaller. This shows that as oscillations become more intense, radial mixing within the meso-tube is increasingly controlled by oscillatory flow than net flow. In this manner, fluid mixing is decoupled from net flow in this OFM device.

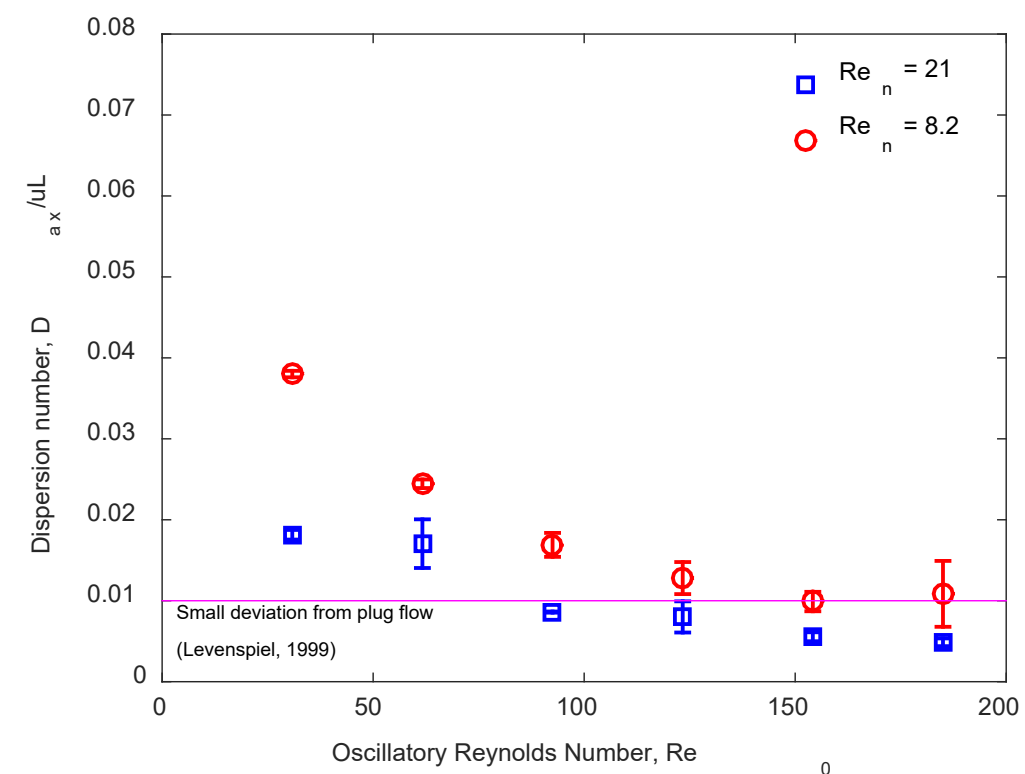

Figure $15 D_{a x} / u L$ determined from dye tracer dual backlit imaging measurements as a function of $R e_{o}$ for different net flow rates. $S t=0.8 ; f=2-12 \mathrm{~Hz}$.

Figure 16 shows the effect of $S t$ on $D_{a x} / u L$. In the case of no oscillation, a $D_{a x} / u L$ of 0.064 was obtained, indicating that dispersive transport was dominant in the test section. For such condition, the flow is laminar and significant axial velocity gradients exist between the 
wall and centre of the meso-tube, hence RTD is broad. A similar $D_{a x} / u L$ value was obtained by Zheng and Mackley [18] for non-oscillatory flow in the same OFM device. The coupling of net flow with a smooth fluid oscillation at $R e_{o}=31(S t=0.8, f=2 \mathrm{~Hz})$ drastically reduced $D_{a x} / u L$ to 0.0182 , highlighting the benefits of oscillatory flow for improved RTD performance. With the introduction of a small fluid oscillation, vortices are formed in the interconstriction regions, which disrupt axial velocity profiles and induce radial mixing; in this way dispersive transport is limited. The SPC mesoscale crystalliser was found to show more sensitivity to changes in $S t$ than $f$, as opposed to a conventional sharp-edged oscillatory baffled reactor (SEPC OBR) [12]. For instance, at $f=2 \mathrm{~Hz}$, halving $S t$ from $0.8\left(R e_{o}=31\right)$ to 0.4 $\left(R e_{o}=62\right)$ increased $D_{a x} / u L$ by 0.0088 ; doubling $f$ from $2 \mathrm{~Hz}\left(R e_{o}=31, S t=0.4\right)$ to $4 \mathrm{~Hz}$ $\left(R e_{o}=62, S t=0.4\right)$ only decreased $D_{a x} / u L$ by 0.0011 . Again, halving $S t$ from 0.4 to 0.2 also increased $D_{a x} / u L$ for the range of $R e_{o}=62-185$, however for $R e_{o}>185$, this $S t$ effect on $D_{a x} / u L$ was less pronounced. This greater sensitivity to $S t$ has been reported in other mesoscale OFRs [13,20,21].

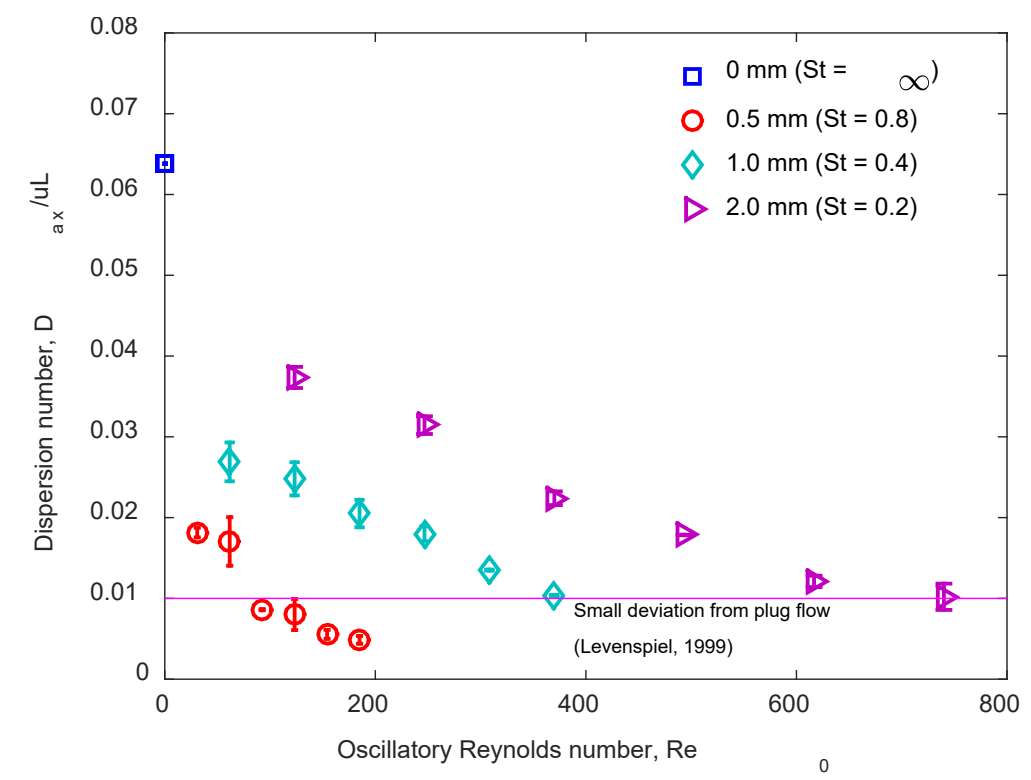


Figure $16 D_{a x} / u L$ determined from dye tracer measurements as a function of $R e_{o}$ at different Strouhal numbers. $R e_{n}=21 ; f=2-12 \mathrm{~Hz}$.

The effect of $S t$ on axial dispersion is such that an effective minimum is achieved at $S t=$ $0.8\left(x_{0}=0.5 \mathrm{~mm}\right)$, followed by a gradual worsening with decreasing St (increasing $\left.x_{0}\right)$. This is similar behaviour to that observed by Zheng and Mackley [18] for the same OFM device in the range of $R e_{n}=10-19$. The results also confirm findings by Mohd Rasdi et al. [39] for a similar SPC design where optimum plug flow was obtained at $S t=0.8$. At $S t<0.8$ the size of eddies generated is bigger, and vortices tend to propagate into adjacent inter-constriction cavities thereby promoting axial dispersion. On the other hand, a gradual increase in $f$ narrows the RTD by increasing radial mixing for all St. Minimum dispersion was obtained at $12 \mathrm{~Hz}$ for all $S t$ investigated. This corresponds to findings by Zheng and Mackley [18], where minimum $D_{a x} / u L$ values occurred between $f=10-12 \mathrm{~Hz}$. Previous work by Reis et al. [14] for a similar SPC mesoscale OFR has shown that above $12 \mathrm{~Hz}$ significant worsening of RTD performance occurs for $S t=0.8$; thus, a turning point is observed. Cruz et al. [16] observed the worsening of RTD performance at a turning point of $4.5 \mathrm{~Hz}$ in an $8 \mathrm{~mm}$ i.d. SPC planar OFC. Phan and Harvey [20] also observed a turning point at $3 \mathrm{~Hz}$ in a $5 \mathrm{~mm}$ i.d. mesoscale OFR with integral baffle design.

Minimum $D_{a x} / u L$ values of $4.9-8.6 \times 10^{-3}$ were obtained in the region of $R e_{o}=93-$ 185 for different oscillation $f$ at $S t=0.8$. This corresponded to a $\varphi$ of $4-9$ which is in the range reported for optimal plug flow performance in mesoscale OFRs [17]. As expected, minimum $D_{a x} / u L$ values obtained by Zheng and Mackley [18] were in a lower range of $1.0-$ $2.0 \times 10^{-3}$ for a test section $\sim 2.6$ times longer than the length of $L$ used in this work. This suggests that for the full-length SPC mesoscale crystalliser $(L \sim 5.4 \mathrm{~m})$ plug flow operation will be achieved at oscillatory $f>6 \mathrm{~Hz}$ for all $S t$ investigated here. Interestingly, for $S t<0.8$, higher oscillation frequencies were required to achieve similar $D_{a x} / u L$ values to those obtained 
for $S t=0.8$, suggesting an undesired lower efficiency of mixing at lower $S t$. A minimum axial dispersion coefficient, $D_{a x}$, of $7.8 \times 10^{-5} \mathrm{~m}^{2} \mathrm{~s}^{-1}$ was obtained for the liquid phase, and this is in good agreement with the value determined by Zheng and Mackley [18] of $6.3 \times 10^{-5} \mathrm{~m}^{2} \mathrm{~s}^{-1}$.

The behaviour of the SPC mesoscale crystalliser suggests that operating at low $x_{0}$ and high $f$ minimises axial dispersion and favours plug flow like performance. Results have shown that for conventional SEPC OBRs $\left(12-69 \mathrm{~mm}\right.$ i.d.), relatively lower $f$ and higher $x_{0}$ favour plug flow behaviour. Oliva et al. (2018) identified optimal operating conditions as $x_{0}=1 \mathrm{~mm}$ and $f=1 \mathrm{~Hz}$ in a $15 \mathrm{~mm}$ i.d. COBR. Stonestreet and van der Veeken [12] observed minimum dispersion at $x_{0}=2 \mathrm{~mm}$ and $f=1-2 \mathrm{~Hz}$ in a $24 \mathrm{~mm}$ i.d. OFR. Siddique et al. [36] also observed an effective minimum value of axial dispersion at $x_{0}=1 \mathrm{~mm}$ and $f=1-4 \mathrm{~Hz}$ in a $69 \mathrm{~mm}$ i.d. OBC. This contrast with mesoscale OFRs is mainly attributed to differences in the fluid oscillation requirement with respect to volume. It follows that larger volume (conventional) SEPCs require higher input axial velocities (at the same $f$ ) to generate substantial radial velocities that have any significant effect on axial dispersion. On the contrary, small-volume mesoscale OFRs like the SPC mesoscale crystalliser would require only a small $x_{0}$ to generate sufficient radial velocities. Since oscillation $f$ governs the rate of eddy generation, small-volume OFRs can handle higher $f$ without creating an imbalance between eddy generation and propagation; as increasing $f$ only serves to optimise the radial distribution of the tracer within inter-constriction cavities. However, with higher $x_{0}$ required for effective eddy propagation in large-volume SEPCs, it is possible that high $f$ creates an imbalance and radial mixing breaks down [40]. 


\subsection{Solid phase RTD studies}

Results from liquid phase RTD studies identified $S t=0.8\left(x_{0}=0.5 \mathrm{~mm}\right)$ as most favourable for minimising axial dispersion in the SPC mesoscale crystalliser. Accordingly, it was necessary to compare the axial dispersion experienced by a suspension of polystyrene particles for a range of frequencies at this $S t$. Experiments were performed at a flow rate of 5 $\mathrm{ml} \min ^{-1}\left(R e_{n}=21\right)$ and at oscillatory conditions $x_{0}=0.5 \mathrm{~mm}$ and $f=2,4,6,8,10,12 \mathrm{~Hz}$ giving an investigated mixing range of $R e_{o}=31-185$. In the absence of oscillatory flow, particles injected into the test section settled to the bottom of the meso-tube due to insufficient radial velocity to overcome particle settling velocity $\left(u_{p}=0.0044 \mathrm{~m} \mathrm{~s}^{-1}\right)$. The introduction of sufficient fluid oscillation achieved off-bottom suspension of particles in all experiments i.e. peak oscillatory velocity, $u(t)_{\max }=2 \pi f x_{0}$, required for particle suspension ranged from $0.0063-0.0377 \mathrm{~m} \mathrm{~s}^{-1}$. Figure 17 shows the normalised input and output curves and the corresponding model response curves, $M(\theta)$, obtained from particle tracer measurements over the range of $R e_{o}=31-185(S t=0.8, f=2-12 \mathrm{~Hz})$. A similar trend is observed in the $M(\theta)$ curves become increasingly narrower as $f$ is increased, indicating less spread of solid particles in the test section. 
(a)

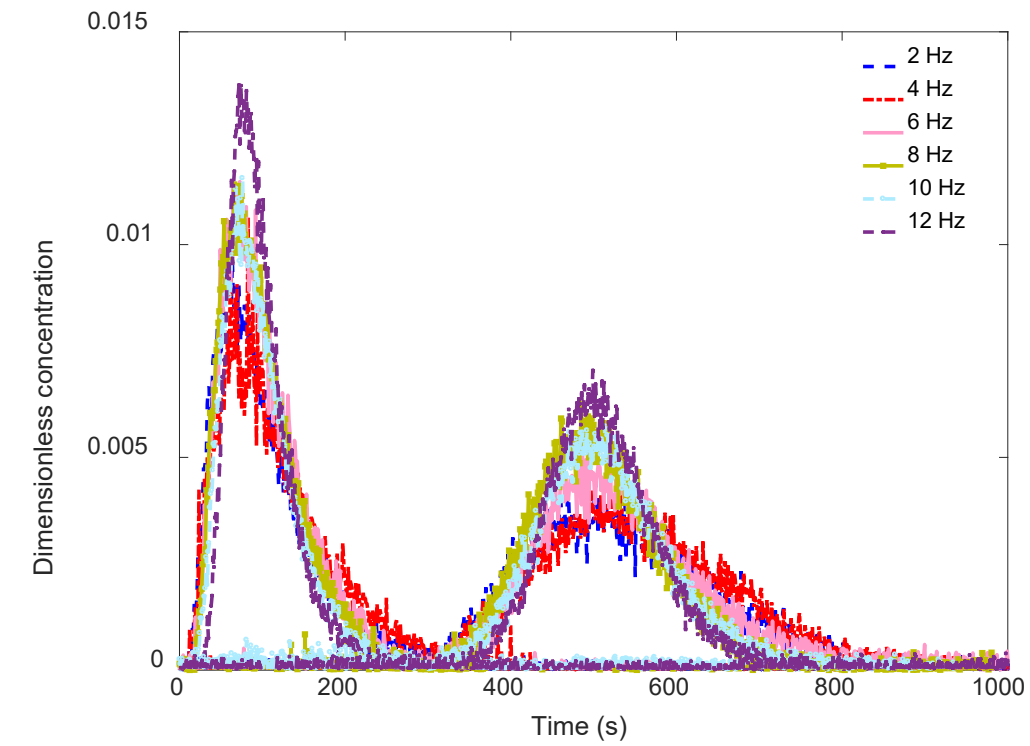

(b)

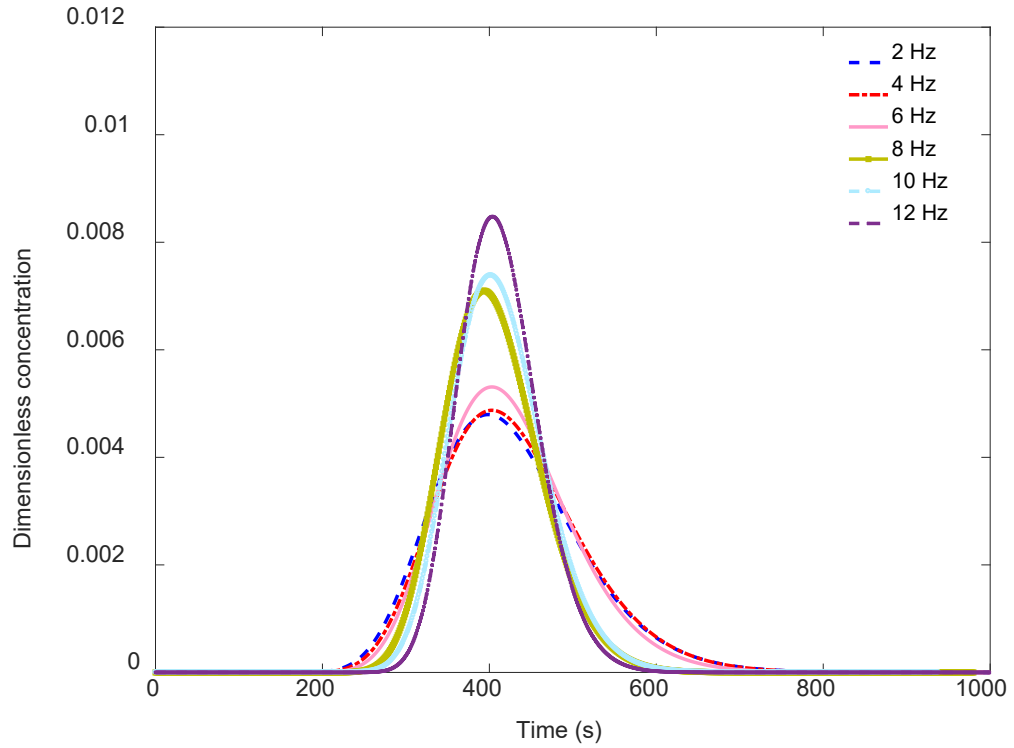

Figure 17 (a) Normalised input and output curves from particle tracer dual backlit imaging measurements (b) Model response, $M(\theta)$, for the solid phase. $R e_{n}=21, R e_{o}=31-185, S t=0.8$.

Figure 18 shows $D_{a x} / u L$ of the liquid and solid phase as a function of $R e_{o}$. At a relatively low $R e_{o}$ of 31 ( $f=2 \mathrm{~Hz}$ ), particles experience significantly more dispersion than the continuous phase due to poor radial mixing in the tube. With poor radial mixing, the particle settling velocity dominates, and particles do not flow with the bulk fluid. The fluid radial velocity must therefore be significantly higher than the particle settling velocity to achieve efficient suspension. It is evident that increasing oscillation $f$ facilitates better particle suspension and allows particles experience similar flow conditions to the liquid phase. At 
$R e_{o}=185$, where $u(t)_{\max }$ is more than sufficient to effectively suspend particles, $D_{a x} / u L$ of the solid phase falls well within the plug flow region $\left(6.5 \times 10^{-3}\right)$ and close to the value for the liquid phase $\left(4.9 \times 10^{-3}\right)$. This indicates that density effects are largely suppressed, although not completely overcome since the solid phase is unable to experience the same degree of dispersion as the liquid phase. Since both phases sharing the same RTD is not of paramount importance, as long as they are within the region of plug flow, operating at $R e_{o}$ of 185 would be less efficient since it requires a higher energy input. A trade-off with a lower energy input may therefore be achieved for polystyrene particles by operating at an $R e_{o}$ of $93(S t=0.8$, $f=6 \mathrm{~Hz}$ ) in the full-length SPC mesoscale crystalliser having an $L$ of $5.4 \mathrm{~m}$.

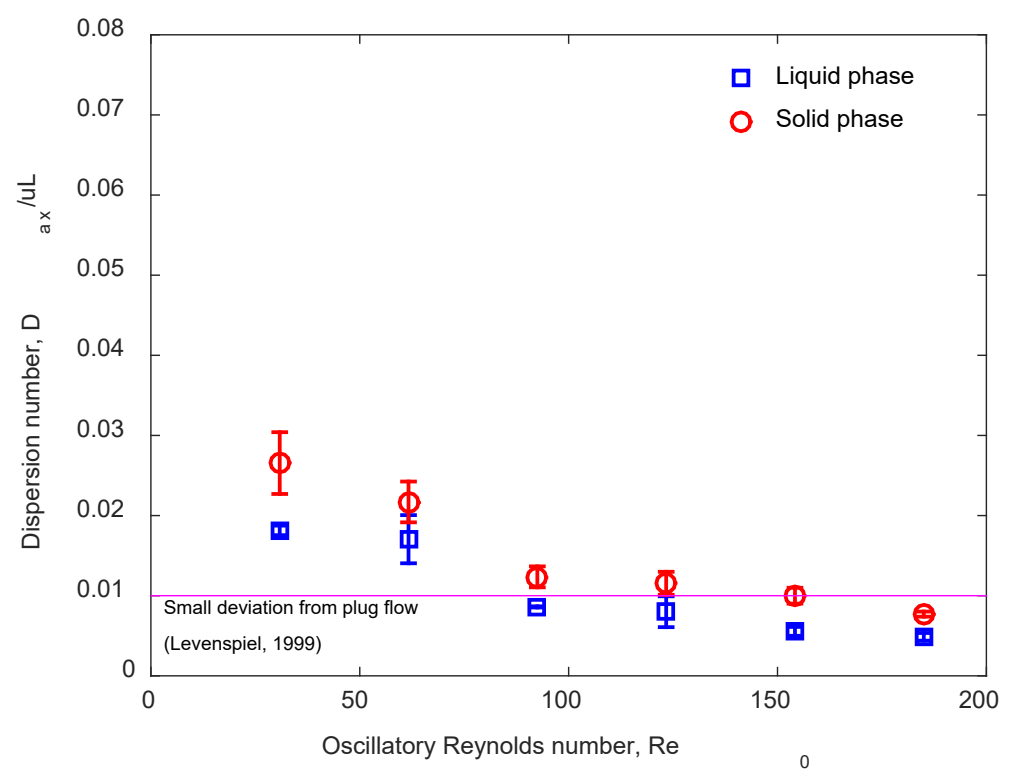

Figure $18 D_{a x} / u L$ as a function of $R e_{o}$ for the liquid and solid phase. $R e_{n}=21, S t=0.8$.

Figure 19 shows that polystyrene particles spent more time in the test section for all frequencies investigated, with the longest mean residence times occurring at lower $f$. This is consistent with observations in other mesoscale OFRs. Cruz et al. [16] observed that solids on average spent $6 \%$ longer in the mesoscale planar OFCs than liquids. Ejim et al. [15] obtained 
a $17-52 \%$ difference between the solid mean residence time and the hydraulic time in 10 mesoscale OFRs studied. Kacker et al. [22] also observed longer times spent by solids in a 15 mm i.d. COBC.

As expected at higher $f$, the time spent in the test section was closer to that of the dye tracer. It is worth stating that these results are for solids with a density closer to that of the bulk fluid. For APIs with much higher crystal densities and settling velocities, we can expect greater differences in mean residence times and axial dispersions experienced by the solid and liquid phase. Thus, it is necessary to investigate these as well. The minimum axial dispersion coefficient, $D_{a x}$, of the solid phase was determined as $1.0 \times 10^{-4} \mathrm{~m}^{2} \mathrm{~s}^{-1}$. This agrees well with the range $1.0-2.2 \times 10^{-4} \mathrm{~m}^{2} \mathrm{~s}^{-1}$ obtained by Ejim et al. [15] in similar mesoscale OFRs.

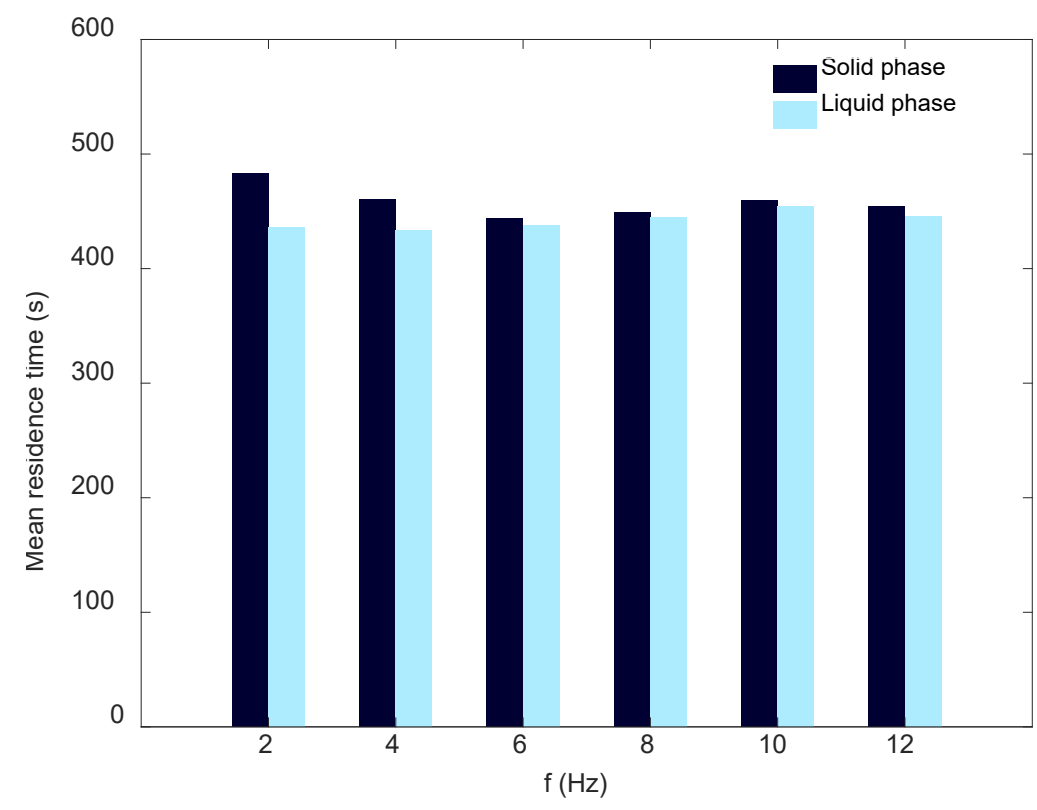

Figure 19 Mean residence times of the solid and liquid phase for different $f$. $R e_{n}=21, S t=0.8$.

\section{Conclusions}

In this work, non-invasive dual backlit imaging has enabled the direct comparison of liquid and solid phase hydrodynamic dispersion parameters in the SPC mesoscale crystalliser. Results 
of liquid and solid phase RTD studies have confirmed that the SPC mesoscale crystalliser can provide solid-liquid plug flow at low net flow rates for crystallisation processes. It has been established that low $x_{0}$ and high $f$ favour plug flow performance in the SPC mesoscale crystalliser, in sharp contrast to relatively higher $x_{0}$ and lower $f$ preferred by conventional SEPC OBRs.

Speculations about the flow behaviour of solids in the SPC mesoscale crystalliser have been tested. Injected polystyrene particles were found to experience a higher degree of dispersion at the conditions identified for optimum liquid axial dispersion performance. The particles were also found to spend longer times in the system compared to the liquid phase. Based on these results, an operating range of $R e_{0}=93-185(\varphi=4-9)$ was identified for solid-liquid plug flow in the SPC mesoscale crystalliser. More importantly, this work has demonstrated that even for small and less dense particles in flow, significant differences exist between liquid and solid axial dispersion experienced at low mixing intensities. However, by operating at near plug flow conditions where radial velocities are higher, particles can experience similar dispersion characteristics as the bulk solution in a continuous crystallisation process.

These results emphasise the importance of characterising the flow behaviour of an API of interest during continuous crystallisation development. This ensures that minimum dispersion operating conditions are appropriately identified for solid-liquid plug flow crystallisation. In addition, the separate liquid and solid axial dispersion coefficients can be accurately determined for in silico modelling. Where APIs are difficult to work with i.e. fouling on tube walls, substitute particles with similar densities and shapes may be used with the noninvasive method developed herein. Overall, the results for the homogeneous and heterogeneous phases show that the SPC mesoscale crystalliser gives precise control of the hydrodynamic experience through careful manipulation of oscillatory conditions and net flow. This is essential 
for effectively operating continuous crystallisation processes to obtain consistent particle attributes.

\section{Funding}

This work was supported by the EPSRC Centre for Innovative Manufacturing in Continuous Manufacturing and Crystallisation (CMAC) (EP/I033459/1) and the Doctoral Training Centre in Continuous Manufacturing and Crystallisation (EP/K503289/1). All data and code created during this research are openly available from the Loughborough University data repository at https://doi.org/10.17028/rd.lboro.9822947.

Declarations of interest: none

\section{Notation}

Abbreviations

API Active pharmaceutical ingredient

COBC Continuous oscillatory baffled crystalliser

COBR Continuous oscillatory baffled reactor

FTIR Fourier transform infrared

OBR Oscillatory baffled reactor

OFC Oscillatory flow crystalliser

OFM Oscillatory flow mixing

OFR Oscillatory flow reactor

PFC Plug flow crystalliser

RTD Residence time distribution 
SEPC Sharp-edged periodic constriction

SPC Smooth periodic constriction

Symbols

C Concentration at any measured time $\left(\mathrm{g} \mathrm{l}^{-1}\right)$

$C^{*} \quad$ Dimensionless concentration for tracer

$C^{*}(\theta) \quad$ Model response

$C_{0}^{*}(\theta) \quad$ Normalised input signal

$C_{1}^{*}(\theta) \quad$ Output response

$C_{D} \quad$ Drag coefficient

$C_{i} \quad$ Initial concentration of species $\left(\mathrm{g} \mathrm{l}^{-1}\right)$

c Particle or dye concentration $\left(\mathrm{g} \mathrm{ml}^{-1}\right)$

D Internal diameter of the tube (m)

$D_{a x} \quad$ Axial dispersion coefficient $\left(\mathrm{m}^{2} \mathrm{~s}^{-1}\right)$

$D_{a x} / u L \quad$ Axial dispersion number

$D_{\text {mean }} \quad$ Mean internal diameter of the tube (m)

$d_{0} \quad$ Inner constriction diameter $(\mathrm{m})$

$d_{p} \quad$ Mean diameter of particles (m)

$f \quad$ Oscillation frequency

$g \quad$ Acceleration due to gravity $\left(\mathrm{m} \mathrm{s}^{-2}\right)$

I Measured intensity through the suspension or dye $\left(\mathrm{W} \mathrm{m}^{-2}\right)$

$I_{0} \quad$ Incident light intensity $\left(\mathrm{W} \mathrm{m}^{-2}\right)$

$L \quad$ Length of test section or distance between measurement points (m)

$L_{S P C} \quad$ Length of an SPC meso-tube (m)

$l \quad$ Mean spacing between constrictions (m) 


\begin{tabular}{|c|c|}
\hline$l_{p}$ & Optical path length (m) \\
\hline$M(\theta)$ & System transfer function \\
\hline$n$ & Number of tanks-in-series \\
\hline$Q$ & Volumetric flow rate $\left(\mathrm{m}^{3} \mathrm{~s}^{-1}\right)$ \\
\hline$R e_{n}$ & Net flow Reynolds number \\
\hline$R e_{o}$ & Oscillatory Reynolds number \\
\hline$S t$ & Strouhal number \\
\hline$t$ & Measured time (s) \\
\hline$u$ & Superficial velocity $\left(\mathrm{m} \mathrm{s}^{-1}\right)$ \\
\hline$u(t)_{\max }$ & Peak oscillatory velocity $\left(\mathrm{m} \mathrm{s}^{-1}\right)$ \\
\hline$u_{p}$ & Maximum steady-state settling velocity \\
\hline$V$ & Inner volume of the tube $\left(\mathrm{m}^{3}\right)$ \\
\hline$V_{\text {cell }}$ & Volume of each inter-constriction cell $\left(\mathrm{m}^{3}\right)$ \\
\hline$V_{d}$ & Volume displaced peak-to-peak in a complete oscillation $\left(\mathrm{m}^{3}\right)$ \\
\hline$V_{S P C}$ & Measured volume in an SPC meso-tube $\left(\mathrm{m}^{3}\right)$ \\
\hline$x$ & Position along the axial length (m) \\
\hline$x_{0}$ & Centre-to-peak oscillation amplitude (m) \\
\hline$z$ & Dimensionless length \\
\hline
\end{tabular}

Greek letters

$\begin{array}{ll}\rho_{c} & \text { Crystal density }\left(\mathrm{kg} \mathrm{m}^{-3}\right) \\ \rho_{p} & \text { Particle density }\left(\mathrm{kg} \mathrm{m}^{-3}\right) \\ \alpha & \text { Open cross-sectional area } \\ \theta & \text { Dimensionless time } \\ \mu & \text { Fluid viscosity (Pa s) }\end{array}$




$\begin{array}{ll}\rho & \text { Fluid density }\left(\mathrm{kg} \mathrm{m}^{-3}\right) \\ \tau & \text { Characteristic time or mean residence time in the test section (s) } \\ \varphi & \text { Velocity ratio } \\ \epsilon & \text { Molar absorptivity coefficient }\left(\mathrm{M}^{-1} \mathrm{~cm}^{-1}\right)\end{array}$

\section{References}

[1] Van Dijck, W., Process and apparatus for intimately contacting fluids, US Patent $2,011,186,1934$.

[2] Howes, T., Mackley, M., Roberts, E., The simulation of chaotic mixing and dispersion for periodic flows in baffled channels, Chem. Eng. Sci. 46 (1991) 1669-1677.

[3] Reis, N., Harvey, A., Mackley, M., Vicente, A., Teixeira, J., Fluid mechanics and design aspects of a novel oscillatory flow screening mesoreactor, Trans. IChemE 83 (2005) 357 $-371$.

[4] McGlone, T., Briggs, N.E.B., Clark, C.A., Brown, C.J., Sefcik, J., Florence, A.J., Oscillatory Flow Reactors (OFRs) for Continuous Manufacturing and Crystallisation, Org. Process Res. Dev. 19 (2015) 1186-1202. https://doi.org/10.1021/acs.oprd.5b00225.

[5] Zheng, M., Skelton, R. L., Mackley, M. R., Biodiesel reaction screening using oscillatory flow meso reactors, Journal of Process Safety and Environmental Protection, 85 (2007) $365-371$.

[6] Smith, K.B., The scale-up of oscillatory flow mixing, $\mathrm{PhD}$ thesis, University of Cambridge, 1999.

[7] Castro, F., Ferreira, A., Rocha, F., Vicente, A., Teixeira, J. A., Precipitation of hydroxyapatite at $37^{\circ} \mathrm{C}$ in a meso oscillatory flow reactor operated in batch at constant power density, AIChE J. 59 (2013) 4483 - 4493. 
[8] Castro, F., Ferreira, A., Teixeira, J. A., Rocha, F., Protein crystallisation as a process step in a novel meso oscillatory flow reactor: study of lysozyme phase behavior, Cryst. Growth Des. 16 (2016) 3748-3755. doi: 10.1180/minmag.1997.061.404.09.

[9] Cruz, P., Rocha, F., Ferreira, A., Effect of operating conditions on batch and continuous paracetamol crystallization in an oscillatory flow mesoreactor, Cryst. Eng. Comm. 18 (2016) 9133 - 9121. doi: 10.1039/c6ce01648k.

[10] Fitch, A. W., Jian, H., Ni, X., An investigation of the effect of viscosity on mixing in an oscillatory baffled column using digital particle image velocimetry and computational fluid dynamics simulation, Chem. Eng. J. 112 (2005) 197-210.

[11] Mackley, M.R., Ni, X., Mixing and dispersion in a baffled tube for steady laminar and pulsatile flow, Chem. Eng. Sci. 46 (1991) $3139-3151$.

[12] Stonestreet, P., van der Veeken, P.M.J., The effects of oscillatory flow and bulk flow components on the residence time distribution in baffled tube reactors, Trans IChemE, Part A, Chem. Eng. Res. Des. 77 (1999) $671-684$.

[13] Reis, N., Vicente, A.A., Teixeira, J.A., Mackley, M.R., Residence times and mixing of a novel continuous oscillatory flow screening reactor, Chem. Eng. Sci. 59 (2004) 4967 4974.

[14] Reis, N., Vicente, A. A., Teixeira, J. A., Liquid backmixing in oscillatory flow through a periodically constricted meso-tube, Chem. Eng. Processing 49 (2010) $793-803$.

[15] Ejim, L. N., Yerdelen, S., McGlone, T., Onyemelukwe, I., Johnston, B., Florence, A. J., Reis, N. M., A factorial approach to understanding the effect of inner geometry of baffled mesoscale tubes on solids suspension and axial dispersion in continuous, oscillatory liquid-solid plug flows, Chem. Eng. J. 308 (2017) 669 - 682.

[16] Cruz, P., Silva, C., Rocha, F. and Ferreira, A., The axial dispersion of liquid solutions and solid suspensions in planar oscillatory flow crystallizers, AIChE J. 65 (2019) e16683. 
[17] Phan, A. N., Harvey, A. P., Lavender, J., Characterisation of fluid mixing in novel designs of mesoscale oscillatory baffled reactors operating at low flow rates $(0.3-0.6$ ml/min), Chem. Eng. Proc. 50 (2011) 245 - 263.

[18] Zheng, M., Mackley, M., The axial dispersion performance of an oscillatory flow mesoreactor with relevance to continuous flow operation, Chem. Eng. Sci. 63 (2008) 1788 1799.

[19] Froment, G. F., Bischoff, K.B., Chemical reactor analysis and design, John Wiley \& Sons, New York, 1990.

[20] Phan, A. N., Harvey, A. P., Development and evaluation of novel designs of continuous mesoscale oscillatory baffled reactors, Chem. Eng. J. 159 (2010) $212-219$.

[21] Oliva, J. A., Pal, K., Barton, A., Firth, P., Nagy, Z. K., Experimental investigation of the effect of scale-up on mixing efficiency in oscillatory flow baffled reactros (OFBR) using principal component based image analysis as a novel noninvasive residence time distribution measurement approach, Chem. Eng. J. 351 (2018) 498 - 505. doi: 10.1016/j.cej.2018.06.029.

[22] Kacker, R., Regensburg, S. I., Kramer, H. J. M., Residence time distribution of dispersed liquid and solid phase in a continuous oscillatory flow baffled crystalliser, Chem. Eng. J. 317 (2017) 413-423. doi: 10.1016/j.cej.2017.02.007.

[23] Rielly, C. D., Marquis, A. J., A particle's eye view of crystalliser fluid mechanics, Chem. Eng. Sci. 56 (2001) 2475-2493. doi: 10.1016/S0009-2509(00)00457-7.

[24] Saleemi, A., Onyemelukwe, I. I., Nagy, Z., Effects of a structurally related substance on the crystallisation of paracetamol, Frontiers of Chemical Science and Engineering 7 (2013). doi: 10.1007/s11705-013-1308-7. 
[25] Powell, K. A., Saleemi, A. N., Rielly, C. D., Nagy, Z. K., Periodic steady-state flow crystallisation of a pharmaceutical drug using MSMPR operation, Chemical Engineering and Processing 97 (2015) $195-212$.

[26] Bird, R. B., Stewart, W. E., Lightfoot, E. N., Transport Phenomena, J. Wiley, 12, 905, 2007.

[27] Levenspiel, O., Smith, W.K., Notes on the diffusion-type for the longitudinal mixing of fluids in flow, Chem. Eng. Sci. 6 (1957) $227-233$.

[28] Bischoff, K.N., Levenspiel, O., Fluid dispersion-generalization and comparison of mathematical models - I. Generalization of models, Chem. Eng. Sci. 17 (1962) 245 255.

[29] Levenspiel, O., Chemical Reaction Engineering, 3rd Ed. John Wiley \& Sons, London, 1999.

[30] Taylor, G.I., The dispersion of matter in turbulent flow through a pipe, Proc. Roy. Soc. 225A (1954) $446-468$.

[31] Palma, M., Giudici, R., Analysis of axial dispersion in an oscillatory-flow continuous reactor, Chem. Eng. J. 94 (2003) 189 - 198.

[32] Verlaan, P., Van Eijs, A.M.M., Tramper, J., Van’t Riet K., Luyban, K., Estimation of axial dispersion in individual sections of an airlift-loop reactor, Chem. Eng. Sci. 44 (1989) $1139-1146$.

[33] Obradovic, B., Dudukovic, A., Vunjak-Novakovic, G., Response data analysis of a three phase airlift reactor, Trans IChemE. 75 Part A (1997) $473-479$.

[34] Fitch, A.W., Ni, X., On the determination of axial dispersion coefficient in a batch oscillatory baffled column using laser induced fluorescence, Chem. Eng. J. 92 (2003) $243-253$. 
[35] Ni, X., Sommer de Gélicourt, Y., Neil, J., Howes, T., On the effect of tracer density on axial dispersion in a batch oscillatory baffled column. Chem. Eng. J. 85 (2002) $17-25$. doi: 10.1016/S1385-8947(01)00137-1.

[36] Siddique, H., Brown, C. J., Houson, I., Florence, A. J., Establishment of a continuous sonocrystallisation process for lactose in an oscillatory baffled crystalliser, Org. Process Res. Dev. 19 (2015) $1871-1881$.

[37] Liu, Y. C., Dunn, D., Lipari, M., Barton, A., Firth, P., Speed, J., Wood, D., Nagy, Z. K., A comparative study of continuous operation between a dynamic baffle crystallizer and a stirred tank crystallizer, Chem. Eng. J. 367 (2019) 278-294. doi: 10.1016/j.cej.2019.02.129.

[38] Harvey, A.P., Mackley, M.R., Reis, N., Vicente, A.A., Teixeira, J.A., The fluid mechanics relating to a novel oscillatory flow microreactor. 4th European Congress of Chemical Engineering (2003) Granada, 0-6.4-004.

[39] Mohd Rasdi, F., Phan, A., Harvey, A., Rapid determination of the reaction kinetics of an n-butylbenzaldimine synthesis using a novel mesoscale oscillatory baffled reactor, Procedia Eng. 42 (2012) 1527 - 1539.

[40] Smith, K. B., Mackley, M. R., An experimental investigation into the scale-up of oscillatory flow mixing in baffled tubes, Chem. Eng. Res. Des. 84 (2006) 1001-1011. doi: $10.1205 /$ cherd.05054. 